\title{
Conceptual Model for the Sustainable Rehabilitation of Medium-Size Inner Cities in Europe: Coimbra, Portugal
}

\author{
Jocelyn Reyes Nieto ${ }^{1}$; Luís Simões da Silva²; Vitor Murtinho³; Constança Rigueiro; and Adelino Gonçalves ${ }^{5}$
}

\begin{abstract}
This paper analyzes the causes of the depopulation of urban centers in European medium-size cities, and presents a conceptual model to address this problem, considering that integrated rehabilitation is necessary to attract new inhabitants, based on the retrofitting of buildings from a sustainable point of view, by developing the concept of a new model of city management based in the generation of subsectors in each city quarter and erecting multipurpose infrastructure buildings that provide the sustainable requirements of that population sector. To illustrate its application to European medium-size cities, the model is applied to the city center of Coimbra, Portugal, including a critical characterization of the current situation, identifying the sociocultural and functional requirements for these neighborhoods, highlighting the feasibility of the conceptual model. DOI: 10.1061/(ASCE)UP.1943-5444.0000303. (C) 2016 American Society of Civil Engineers.
\end{abstract}

Author keywords: Urban centers; Rehabilitation; Multipurpose building; Steel solutions.

\section{Introduction}

"Cities change, men also, we have never been so exposed to changes in values. Never the cities had transformed so much and also the construction procedures..." (Sánchez 2009).

Cities are a nexus of needs and opportunities. They offer exceptional possibilities for economic development, social inclusion, and well-being, and they are unique in the cultural and architectural level (European Commission 2009). For this reason, nowadays, more than 75 percent of the European population lives in cities; however, the development and growth of these urban centers did not always occur in a planned manner, causing urban disaggregation (Alonso 2011).

Currently, the most representative problems that induce regeneration processes in European countries are the physical degradation of buildings, the concentration of social problems, the need for new public spaces and equipment, the environmental damage (Servicio de Estudios et al. 2010), and the dramatic increase of the

\footnotetext{
${ }^{1}$ Institute for Sustainability and Innovation in Structural Engineering (ISISE), Dept. of Civil Engineering, Univ. of Coimbra, Rua Luís Reis Santos, Polo II, 3030-788 Coimbra, Portugal (corresponding author). E-mail: jocelyn@student.uc.pt

${ }^{2}$ Institute for Sustainability and Innovation in Structural Engineering (ISISE), Dept. of Civil Engineering, Univ. of Coimbra, Rua Luís Reis Santos, Polo II, 3030-788 Coimbra, Portugal. E-mail: luisss@ dec.uc.pt

${ }^{3}$ Center for Social Studies (CES), Dept. of Architecture, Univ. of Coimbra, Colégio das Artes, Largo D. Dinis, Polo I, 3000-143 Coimbra, Portugal. E-mail: vmurtinho@uc.pt

${ }^{4}$ Institute for Sustainability and Innovation in Structural Engineering (ISISE), School of Technology, Polytechnic Institute of Castelo Branco, Av. Pedro Álvares Cabral No. 12, 6000-084 Castelo Branco, Portugal. E-mail: constanca@ipcb.pt

${ }^{5}$ Center for Social Studies (CES), Dept. of Architecture, Univ. of Coimbra, Colégio das Artes, Largo D. Dinis, Polo I, 3000-143 Coimbra, Portugal. E-mail: amsg@uc.pt

Note. This manuscript was submitted on December 12, 2014; approved on June 30, 2015; published online on January 4, 2016. Discussion period open until June 4, 2016; separate discussions must be submitted for individual papers. This paper is part of the Journal of Urban Planning and Development, (C) ASCE, ISSN 0733-9488.
}

metabolism of cities (the inflow of water, energy and materials, and outflow of wastes) (Codoban and Kennedy 2008).

These days, residential and tertiary buildings (commercial and public) are the largest users of energy, representing 41 percent of the total energy use across all building sectors (Gervásio et al. 2010) and they are seen as offering the greatest potential for energy and $\mathrm{CO}_{2}$ reduction. It is further noted that the European Union (EU) mainly depends on external energy sources with a predicted import rate of 70 percent by 2030 , compared to 50 percent today (Labory et al. 2008).

Responding to these problems and bearing in mind that people in industrialized countries spend about 90 percent of their lifetime inside buildings (Bronsema et al. 2004), European countries have implemented several new strategies to rehabilitate and reintegrate the urban and architectural development in a sustainable way. The following examples illustrate this statement: The European Commission (EC) launched the GreenBook (Nijkampp and Perrels 1994), a concept whereby companies integrate social and environmental concerns in their business operations; the Organization for Economic Cooperation and Development (OECD) published its report on Environmental Policies for Cities (Nijkampp and Perrels 1994); the Urban Community Initiative encouraged European urban areas and neighborhoods in crisis to design innovative, integrated urban development measures (Europa-URBAN II 2013); the Urban II Community Initiative implemented strategies for sustainable economic and social regeneration of small- and mediumsize cities (Europa-URBAN II 2013); the Global Partnership for Sustainable Development implemented a strategy for sustainable development (Europa_-Global Partnership for Sustainable Development 2013); the European Observatory Network in Luxemburg (ESPON), published a study titled "The Role of Small and Medium-sized Towns in Europe," which explored the urban functions and the role of small and medium-size cities in regional developments in the beginning of the 21st century (Rahaman et al. 2012); the Joint European Support for Sustainable Investment in City Areas (JESSICA) initiative gives financial support for sustainable investment (JESSICA 2013); and the European Energy Program for Recovery designs new types of energy supplies (EEPR 2013).

Nevertheless, the problems experienced in European urban centers are not only technical as they also involve lifestyles. The urban 
environment is not an industry or a technical issue; it is the central point between quality of life and sustainability. Consequently, an important objective in European urban centers is to improve the habitability of the neighborhoods of the cities, with criteria of equity in the production processes, social efficiency, and environmental quality of life (Arias 2001).

This paper presents a conceptual model for the sustainable rehabilitation and management of inner centers in European medium-size cities (in the range of 50,000-500,000 inhabitants). The innovative aspect lies in the development of a decentralized management model that directly empowers the population at a district level. It is combined with the application of sustainability concepts at the urban level instead of applying them only at the building level, coupled with the use of advanced construction techniques to minimize impacts and disruption during the rehabilitation process. Empowering the population could be implemented by using nonfinancial compensation systems based on the attribution of transferable and tradable development rights or other types of benefits (such as reduced fees) to those who meet preestablished goals by local councils, such as the reuse of vacant buildings for residential purposes or the reduction of energy consumption.

\section{Main Problematic of European Urban Centers}

The major problem of the cities is structural and is called urban disaggregation. Some of its aspects have localized expressions, such as the degradation of the buildings and the depopulation of the central and older urban areas, but the problem cannot be solved only with localized actions.

The rehabilitation of substandard buildings of the central and older urban areas alone does not solve the problem of urban depopulation. For this, it is necessary to provide these urban areas with characteristics that make them desirable and competitive with all residential areas of a city.

\section{Urban Desertification}

As mentioned earlier, the European population tends to live in cities, creating a widespread urban lifestyle and a strong imbalance between districts. It is well known that the neighborhoods with higher comfort and better mobility for the residents are the ones that attract more people; as a result, the old urban centers become progressively uninhabited. This trend leads to certain parts of the city becoming problematic, with poor organization, deterioration in buildings, increased social problems such as insecurity and violence, and so forth. All these issues generate city disaggregation. Therefore, urban policies are necessary to implement direct intervention strategies that constitute driving forces of urban cohesion (European Commission 2011).

Some European countries developed various initiatives to address this problem. In Prague, the Czech Republic, a project was implemented to revitalize neighborhoods by promoting a dynamic regeneration of the inner-city neighborhoods and evaluating the level of residential satisfaction in these neighborhoods (Temelová and Dvoráková 2012). In Coventry and Nottingham, U.K., the city center management and safer city center project discussed the effectiveness of town center management partnerships to promote guided programs to improve the sense of safety in their city centers. The effectiveness of such programs is not just to reduce the actual incidence of offenses, but also to change people's perceptions of their environments, to develop a sense of control, security, and confidence, and also to recover the habitability of these neighborhoods (Oc and Tiesdell 1998).
These projects represent good examples for the resolution of the problems of urban desertification; providing new quality of life for the existing neighborhoods and creating an interaction between all the neighborhoods of each city. However, it is necessary to implement integrated solutions that are easily perceived by investors as much as by municipal councils and by the citizens of each city.

\section{Urban Disaggregation at a District Level (City Configuration)}

The unbalanced distribution of resources creates neighborhoods with higher potential and simultaneously neglects the renewing and restructuring of older neighborhoods, generating loss of interest in the development of these at the district level.

At the forefront of this type of disorder is the problem of mobility. The explosion of the number of vehicles in operation (more than 1 billion by 2011) and the underlying car culture, not only generates complications in the road development, but also in the cities (Urry 2003). Older city districts are not prepared for car circulation because of their narrow streets, their complicated street layouts, and difficult topography. Attempts to transform these neighborhoods to accommodate vehicles usually cause traffic and parking problems, the increase of gray spots in the city, as well as environmental, noise, and visual pollution-the less glamorous parked car shapes daily urban life (Manville and Shoup 2005). Additionally, the cities often are accompanied by drastic changes in function, with residential occupation shifting to business and commercial functions, resulting in further desertification of the city centers.

Extra disorders related to the availability of resources correspond to difficulties in providing adequate services and infrastructures such as waste management and the conciliation between safety of the pedestrians and car use.

\section{Degradation of the Housing Stock}

This problem began to worsen in the 1960s; the resident population was generally working class people who paid low rents for their housing. These low rents prevented the landlords from investing in maintenance, therefore producing deterioration and contributing to the current housing abandonment (Fernández 2012). In this context, it should be noted that the Portuguese government implemented a policy of freezing and controlling rents for social housing throughout the twentieth century.

Also, with the increase of individualization, a loss in the relationship between people and between buildings has occurred (Lipovetsky 2003); within a neighborhood, each building becomes independent, as does its maintenance. Basically, this problem relates to the cause-and-effect relationship between urban and social disaggregation of urban communities.

Another common phenomenon in housing stock is the inability to bring about a social unification of all the residents of the neighborhood. Furthermore, the arrival of new ones causes a structural division within a neighborhood into old and new residents (Fernández 2012).

All these negative externalities show an alarming growth rate, resulting in increasing threats to the housing stock by making it easier for the residents to change their place of living than to invest in the correct maintenance and rehabilitation practices.

In developing countries, such as those in Africa, the issue of urban sustainability has to deal with structural differences in comparison with Europe, in particular the trends in population growth and its impact on the growth of cities. "Sustainable housing for sustainable cities: A policy framework for developing countries" 
and "The transformation of the existing building stock: A precondition for a sustainable future" are examples of research projects that addressed these issues. The first example attempted to generate some conceptual knowledge about housing and sustainable buildings, creating a new understanding of the housing: it was no longer regarded as simply a roof over one's head, but played a crucial role in achieving sustainable development, as envisaged by the idea of sustainable housing (Golubchikov and Badyina 2012). The second example involves the distribution of existing building stock: the evaluation of economic, energetic, environmental, and social aspects of it; the maintenance and rehabilitation of existing buildings with the use of new materials; and the adaption of communities toward self-regulating energy systems (Richner 2013).

In the European context, demographic trends are different, but the issue of urban sustainability is also paramount, as a process of restructuring existing cities.

\section{Energy Efficiency}

The operational energy consumption of residential buildings represents a large proportion of their total energy consumption (Gervásio et al. 2010). In Europe, buildings account for 36 percent of all energy use and residential buildings account for 27.5 percent (Santos et al. 2011). Consequently, the European Directive on the energy performance of buildings (European Parliament 2010) imposed challenging targets for the reduction of energy consumption in buildings.

However, improving the energy efficiency of residential buildings is a complex task because of the number of factors that must be taken into account (Santos et al. 2010):

- First, climate is the main factor that needs to be considered and the range of climatic conditions at the global scale is huge;

- Second, the occupational schedule and social habits also change in a country or regional basis;

- Third, the energy efficiency and thermal performance depend on the local site conditions and building orientation; and

- Finally, the building type and the underlying adopted construction solutions dictate the actual performance of the building.

Redesigning and reconstructing urban habitat is central to addressing crucial global environmental issues (Codoban and Kennedy 2008); however, the inner-city neighborhoods are characterized by an old building stock with below-average energyefficiency performance. This creates an additional difficulty because of the added complexity in implementing efficient cost-effective rehabilitation of existing buildings (almost always combined with structural rehabilitation needs) that minimizes disruption to the neighborhood.

\section{Rehabilitation: Appropriate Use of Materials, Technologies, and Processes}

Inner-city neighborhoods often have to follow strict guidelines concerning architectural heritage. This results in rehabilitation interventions often being delayed because of the lack of response from the local authorities and the discretionary assessments and permits necessary for the work of rehabilitating buildings in a historic urban landscape. A rehabilitation intervention requires additional care in the appropriate use of materials, technologies, and processes that otherwise result in the acceleration of degradation of urban centers, contributing to inhabitability, inferior maintenance, increase in depreciated urban areas, and the generation of more infrastructure and economical problems.

Recent research projects have developed efficient solutions for the sustainable rehabilitation of buildings, such as "Energy
Efficient Buildings through Innovative Systems in Steel" (EEBIS), a research project where technologies and concepts are developed to obtain new steel products and systems for energy-efficient buildings by regulating internal temperatures, reducing heat loss by heat transmission and air infiltration through cladding, using solar collection devices for energy creation, using double-skin facades and roofing systems, and providing heat recovery systems (Labory et al. 2008). "Promotion of steel in sustainable and adaptable buildings" (PROSSUS), presents and disseminates information on the steel construction technologies used in buildings (Lawson et al. 2008); "Renovation of buildings using steel technologies" (ROBUST), addresses the renovation and improvement of existing residential, industrial, and commercial buildings using steel-based technologies (Lawson et al. 2013); "Designing low carbon buildings," presents a design framework and a set of integrated Intelligent Tools to enable an analysis of the energy performance of building designs, including consideration of active and passive renewable energy technologies (Dawood et al. 2013).

However, there is still a need to integrate these results and possibilities into mainstream architectural practice in order to realize the economical benefits of cheaper and more efficient solutions.

\section{General Framework}

As previously described, there is no integral and comprehensive solution that meets all the requirements to overcome the current problems in the centers of European cities. However, their solution will never be solved with separate and casual interventions, but rather with integrated solutions such as that presented in this paper, by its ability to catalyze the regeneration of urban districts with different orders of benefits: social, economic, and functional.

In the following sections, the design framework developed to support the integration of the conceptual model for the sustainable rehabilitation and management of European medium-size inner cities is presented. It consists of the urban level and the building level.

\section{Urban Level}

\section{Description of the Concept}

The examination of a sample of European midsize cities reveals a series of common features with respect to their older districts or neighborhoods. Fig. 1 gives an overview of the central parts of the cities of Coimbra, Portugal; Naples, Italy; and Bruges, Belgium.

Despite the difference in their geographical locations, climates, and cultures, they somehow share the following features:

- Clearly defined sectors characterized by no internal main streets, usually with severe restrictions for car traffic (either physical limitations due to the narrow width of the streets or legal restrictions or both);

- Average age of the building stock in excess of 100 years, with various levels of conservation, ranging from low-rise, two-story buildings to a maximum of seven stories;

- Low availability of parking places and virtually no provision for individual parking in each building. Availability of paid public parking only in the periphery of each sector;

- Low-to-zero availability of green spaces inside each sector; and

- Mixed use, comprising residential functions and small-scale commercial and touristic use, with some services.

The level of occupation of these sectors depends on the wealth and level of organization of society in each country. 


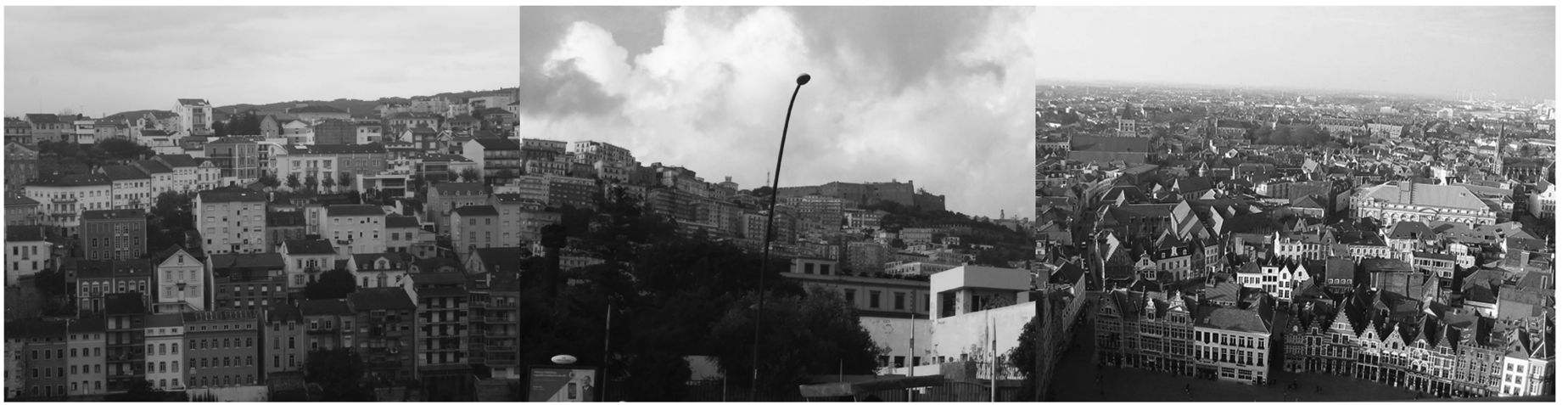

(a)

(b)

Autor: Vitor Murtinho
Autor: Rui Matos (c)

Autor: Donar Reiskoffer

Permission: CC BY-SA 3.0

Fig. 1. European medium-size inner cities: (a) Coimbra, Portugal (image by Vitor Murtinho); (b) Naples, Italy (image by Rui Matos, with permission); (c) Bruges, Belgium (image courtesy of Wikimedia Commons/Donar Reiskoffer)

Bearing in mind the extensive degradation of the building stock, the lack of adaptability to current standard levels of comfort, its abandonment and the corresponding significant depopulation that is presented in the identified cities, it is clear that success in attracting new residents to the inner districts depends on achieving a critical level of occupation in a relatively short time. This includes a balanced mix of social classes, an above-average level of quality of the urban environment, including a significant proportion of refurbished buildings also available in a short period, the possibility of parking cars within a short distance from the residence, and attractive economic conditions for essential services such as electricity and water and reduced transportation costs. The positive differences for real estate offers distinguish these districts from other parts of the city. In short, the management of urban historic centers requires, among other things:

- A proactive and purposeful stance of municipalities; and

- An integrated and multisector planning.

The conceptual model described herein addresses directly most of these issues by proposing the subdivision of the inner districts and sectors in basic units (defined as subsectors) that share a common infrastructure (multipurpose building), according to a specific management plan supported by a versatile business model. In this regard, it should be noted that the banking network established that real estate investments would focus henceforth on urban regeneration and especially in innovative projects that ensure the satisfaction of potential users. The conceptual model does not directly address the issue of the rehabilitation of the existing buildings, but it provides the necessary conditions to attract private investors to carry out that task.

Finally, this conceptual model needs to be supported by appropriate policies from the public sector that provide confidence to the economic players to invest in those neighborhoods. In the Portuguese context, it must be stressed that the governing board of the Instituto da Habitação e da Reabilitação Urbana (IHRU) assumed a new policy in 2012 to reverse the funding models hitherto used that were based on a logic of direct grants, which was inhibiting the assumption of new commitments; e.g., the PROHABITA, RECRIA, REHABITA, and SOLARH programs (Madeira 2009).

\section{Methodology}

Characterization. The first step of implementation of this model is characterization. It includes the transportation network (road infrastructure, parking, and public and private transport), the building stock, including the level of conservation (use of buildings and energy efficiency), the urban infrastructures (water, energy, waste, and sewerage), and the characterization of the residents and the economic flows of that sector.

Spatial Typologies (Subsectors). Analysis of a sample of inner districts from several cities shows that, based on an average size of about 20 buildings, the following four different subsector typologies are sufficient to cover all situations (Fig. 2): (1) multistreets, (2) perimeter streets, (3) middle street, and (4) linear side street.

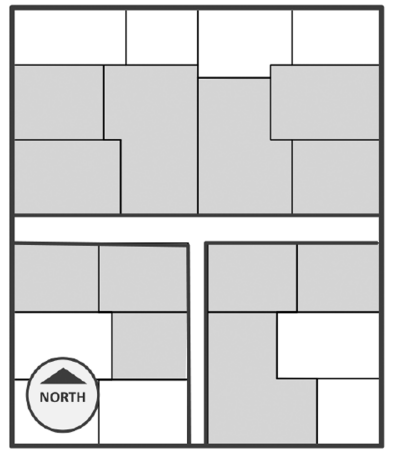

Case 1: Multistreets

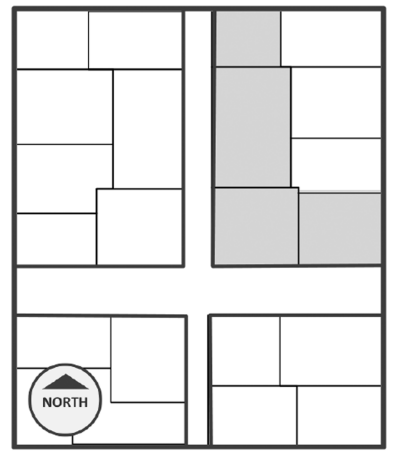

Case 2: Perimeter streets

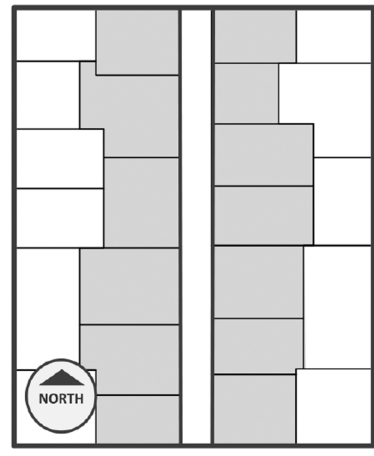

Case 3: Middle streets

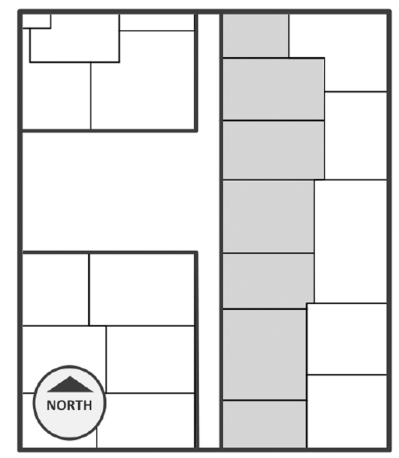

Case 4: Linear side streets

Fig. 2. Typologies of subsectors 


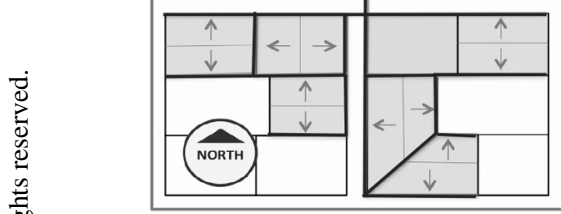

(a)

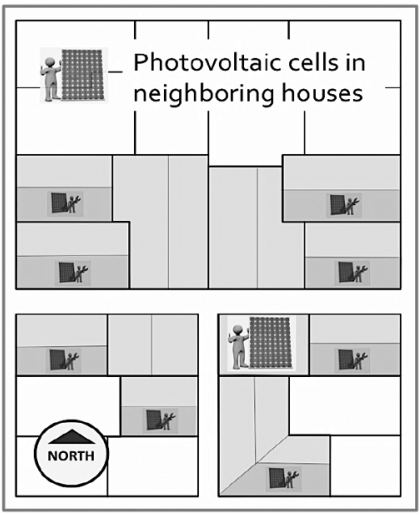

(b)
Fig. 3. City quarter intervention: (a) rainwater harvesting; (b) energy harvesting

Each subsector must be accessible to a car or a standard firefighting vehicle, and also each subsector is fitted with an appropriately sized multipurpose building that will provide the functionalities described in a later section, "Building Level."

Shared Functions and Infrastructures. The organization of a sector into subsectors allows the implementation of two collective solutions: generation of electricity from renewable sources and the collection of rainwater for secondary use. These collective solutions are used to transform urban regions into more productive zones (Leduc and Van Kann 2013); that is, the use of renewable sources as a way to optimize the balance of energy generation and consumption (Goulden et al. 2014), and domestic rainwater harvesting to save potable water in buildings. This approach has become increasingly popular in Europe due to the improved reliability and understanding of system design and realization issues (Palla et al. 2012).

These facilities have their function at the subsector level, each multipurpose building being independent from the others, and they are only supplied to the households of its subsector.

Fig. 3(a) illustrates schematically the possibilities of rainwater harvesting using the roofs of the existing buildings and an appropriate local water collection pipeline network that feeds a reservoir placed inside the multipurpose building for local use at the subsector level. The utilization of this system can help householders achieve significant water savings and avoid the domestic water bills that are due to be reintroduced (Li et al. 2010). Similarly, Fig. 3(b) also illustrates schematically the possibilities for electricity generation from photovoltaic cells placed in the roofs of the buildings, connected to a central accumulation hub located in the multipurpose building, which provides energy to the subsector, either for the operation of the multipurpose building itself, supplying electricity to the residents, public functions (e.g., street lighting), or even selling electricity to the electric companies.

Mobility. The issue of mobility and transportation is essential for the successful redensification of the inner districts. In most cases, public transport is usually restricted to the boundaries of each sector, providing a reasonable service to the residents or visitors to any point inside the sector in terms of walking time/distance from the nearest public stop.

Besides the need to provide access to public vehicles related to city services (waste collection or fire truck), access of the residents' private cars is also necessary as a comfort criterion (transportation of handicapped people, transportation of goods), as is the provision of parking within a small distance from the residence.
Finally, walking and bicycling are also viewed as essential ingredients in an integrated and redensified district, because it gives residents and visitors another transportation option and provides continuity to the city quarters (Southworth 2005).

The multipurpose building provides all of these functions.

\section{Building Level}

\section{Multipurpose Building}

Description of the Concept. The multipurpose building constitutes an essential component of the proposed conceptual model. First, the objective of this building is to provide services and shared infrastructures that increase the attractiveness of the neighborhood for new residents to move in and redensify those sectors of the cities. It shall provide stacked parking for the residents of each subsector, in order to minimize the distance from the parking place to the residence, using automated self-parking systems that maximize the number of parking places per volume and reduce car emissions because parking operations are performed without the use of car engines.

Additionally, the building may provide a list of amenities such as waste sorting, rainwater storage for reuse, management and storage of the electricity production from renewable energy sources within each subsector (photovoltaic, microwind), the provision of a community room for social activities for residents and the implementation of occupational activities for various ages, the creation of a roof garden that may even provide some economic return from horticulture, and a small kiosk at ground level for the establishment of a low-cost microbusiness.

Secondly, the multipurpose building shall be able to address the specific needs of each subsector, being easily scaled up or down to the appropriate number of parking places. This implies that the building is modular, so that it can be easily resized and/or reconfigured. Additionally, the building shall be able to adjust to the available space: Inner districts often exhibit individual land units with irregular dimensions, as will be illustrated in this paper.

From the point of view of planning and construction of the multipurpose building, this shall consist of a preengineered solution that is completely industrialized with quick in situ construction to minimize disruption to the neighborhood and minimize costs. Consequently, no underground occupation of space is considered, but coupled with adequate foundation systems (micropiles, screwed foundations), one can take advantage of the lightweight solutions for the superstructure. This feature of the multipurpose building is very important, in that it can ensure the protection of archaeological heritage and the respect of principles enshrined in international doctrines concerning cultural heritage, in particular, the principle of reversibility established in 1964 by the Venice Charter issued by the International Council on Monuments and Sites (ICOMOS).

Finally, the intervention in inner-city neighborhoods or districts must meet strict guidelines of architectural heritage, which focus mainly on issues of urban image, and they establish that the appearance of facades should be maintained. With regard to the interior of buildings, these guidelines are not fixed and the restrictions and permits are evaluated case by case. However, in situations of extreme degradation of the supporting structure of the buildings, nothing prevents renewal work from being done by keeping only the facades. The multipurpose building should be able to comply with these requirements.

Modularity. In accordance with the modularity requirements for the multipurpose building explained previously, Fig. 4 illustrates the adopted modular grid dimensions. These are strongly determined by the requirement to offer parking for vehicles and are 


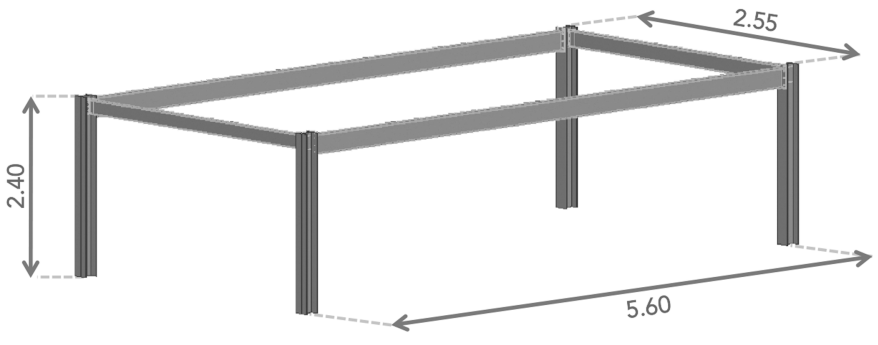

Fig. 4. Modular system dimensions

compatible with the implementation of automated, self-operated stacked parking systems (WÖHR 2012). The minimum modular building plan size consists of either $2.55 \times 11.20 \mathrm{~m}$ or $5.10 \times$ $5.60 \mathrm{~m}$, while the maximum plan size is theoretically unlimited. The number of stories is also not limited.

In order to organize the modular possibilities of the building according to the diversity of services, these modular possibilities were grouped according to the following four classifications: functional, vertical circulation, roof, and facade.

Functional (Fig. 5). This classification provides the main uses and services of the building; it comprises nine different modules. The first three modules correspond to the transport function. Module 1 promotes the sustainable use of ecological transports, such as bicycles and motorcycles. Modules 2 and 3 consist of parking spaces and a parking elevator; they maximize the number of parking spaces in buildings with restricted floor areas.

The following four modules provide services for the residents of each subsector, such as waste collection sorting and recycling (module 4), rainwater treatment for reuse (modules 5 and 6), and alternative energy management (module 7). Basically, with these modules, the building becomes part of the infrastructure of the city, connecting new and existing buildings. Therefore, this effect will not be limited to some new buildings but will affect and rehabilitate entire city quarters, with the added benefits of a local distributed supply network.

Finally, the last two modules of this classifications are developed in order to encourage the social aspects with the creation of a community room for diverse activities (module 8), complemented with a bathroom module (module 9 ).

Vertical circulations (Fig. 6). In this classification, three different alternatives are provided, those correspond to elevator and stairs, stairs only, or maintenance stairs.

Roof (Fig. 7). This classification provides two different functions to develop at the top of the building. The first is of a social nature, which contributes to improving the green areas of the city with a rooftop garden (horticulture module), where the residents can achieve a natural and sustainable culture by producing their own food and gardening for enjoyment as well. Module 14 provides the possibility of installing photovoltaic panels for electricity production or thermal collectors for domestic hot water supply, complementing the electricity generation from the other buildings in the subsector.

Facade (Fig. 8). This classification determines the intervention in the facades of the multipurpose building. It comprises three options: Type A applies to cases of extreme degradation of buildings in which it is only possible to maintain the exterior walls, which in many cases are thick walls requiring special care and rehabilitation. Here, it is crucial to pay particular attention to the connection between the new internal structure and the facade walls. Furthermore, it is often necessary for the new internal structure to provide lateral support to the facades. Type B corresponds to a new facade in lightweight materials that maintain the architectural characteristics and material textures of the original facades. This way, the urban

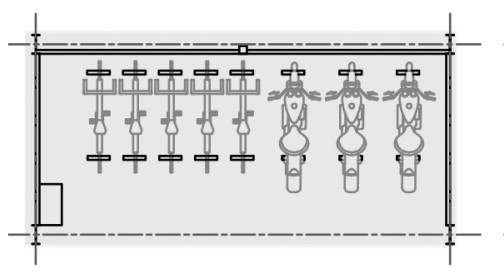

Module 1

Bicycle and motorcycle rental

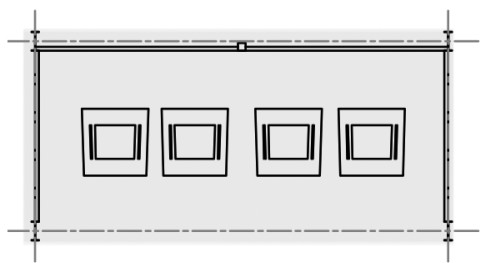

Module 4

Garbage collector

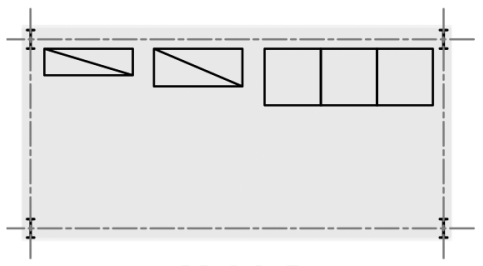

Module 7

Energy efficient development

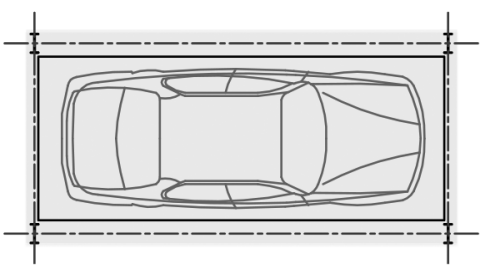

Module 2

Parking lot

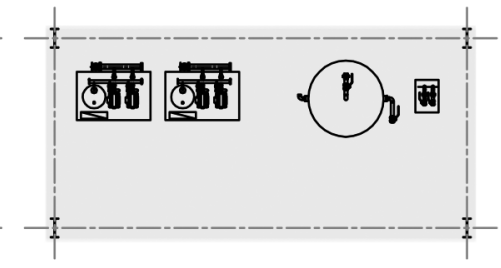

Module 5

Water treatment

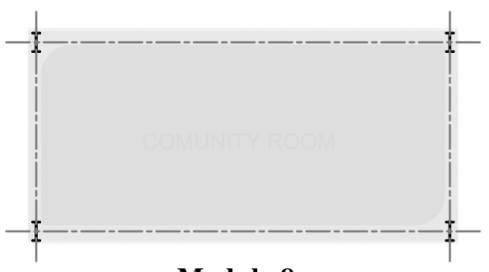

Module 8

Community room

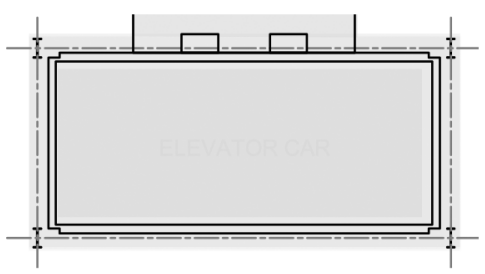

Module 3

Parking elevator

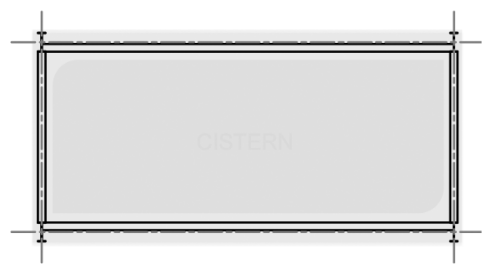

Module 6

Cistern

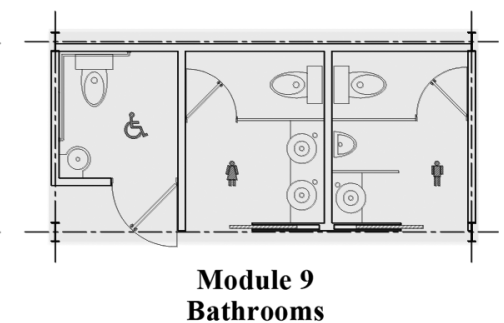

Fig. 5. Functional classification 


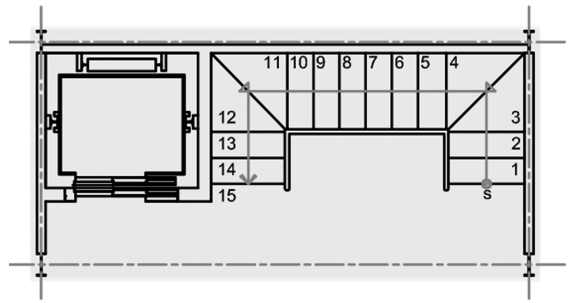

Module 10

Elevator and stairs

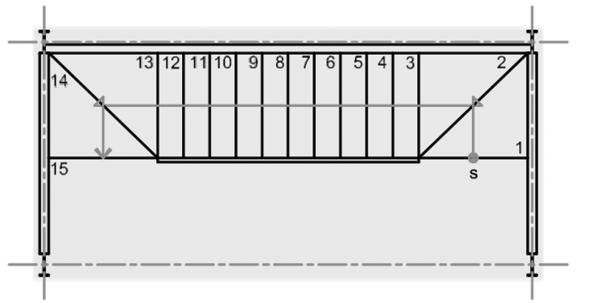

Module 11

Social stairs

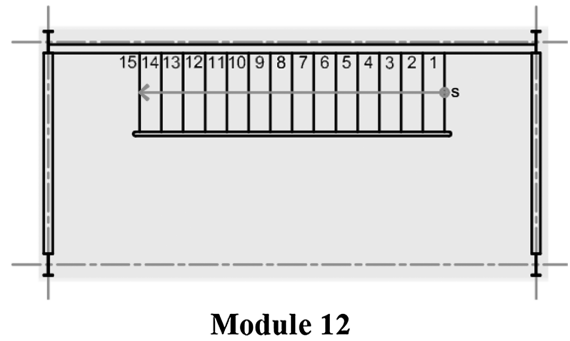

Module 12

Maintenance stairs

Fig. 6. Vertical circulations classification

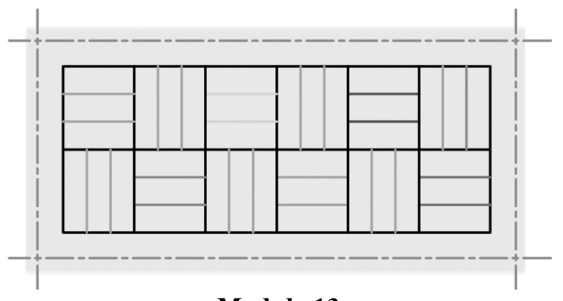

Module 13

Horticulture

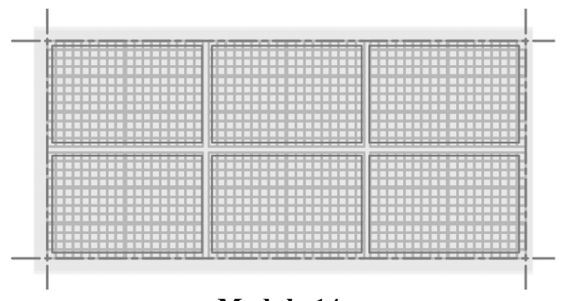

Module 14

Photovoltaic cells

Fig. 7. Roof classification

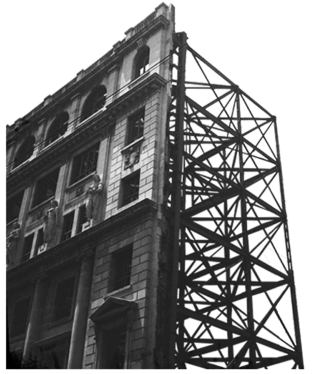

Type A

Existing facade Autor: Gustavo Adolfo Rodriguez Nava
Permission: CC BY-NC-SA 2.0 Permission: CC BY-NC-SA 2.0
This image has been adapted from the origina

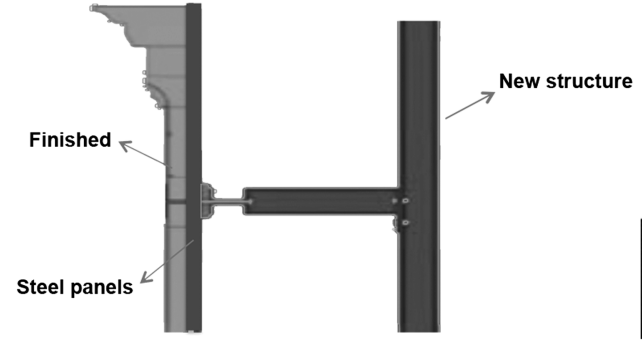

Type B

New structure with apparent finish

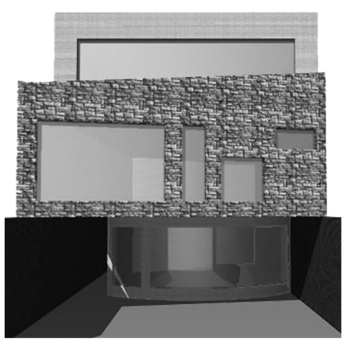

Type C

New model of facade

Fig. 8. Building facade classification (Type A image courtesy of Gustavo A. Rodríguez Nava)

heritage values are maintained in situations where the constituent materials of the facades are too degraded and present no value in themselves. Finally, Type C corresponds to a new facade where innovative textures and contrast with the surrounding building stock is used to provide added value to the subsector; this type also uses lightweight materials, which can be used to construct buildings with its own aesthetic qualities. Typical examples may be found, for instance, in the urban rehabilitation of Graz, Austria, in 2003, for the European Capital of Culture (2009). However, Type C is also a solution that may ensure respect for structural characteristics of ancient urban landscapes; i.e., volume, registration of land, textures, and color.

A final aspect relates to the vehicular accessibility to the multipurpose building, so it is necessary to provide different alternatives, depending on the space available for maneuvering the cars in front of the building and the typologies of the streets. Fig. 9 represents different solutions taking into account two different cases: in the first, there are no restrictions and the cars can access the building perpendicularly to the facade and position themselves directly on the elevator module. In the second case, because of the narrow street, the elevator module needs to load the vehicle directly from the street using lateral rails and ramps.

\section{Remaining Building Stock}

The rehabilitation of the remaining building stock is not covered in this paper. Nevertheless, it constitutes an essential component for the success in attracting new residents to inner-city neighborhoods. It is essential that the rehabilitation interventions minimize the disruption to the remaining residents. This implies the extensive use of prefabricated lightweight solutions that minimize the need for large shipyards and very fast construction cycles. The quality of the resulting interventions needs to be above average in order to 


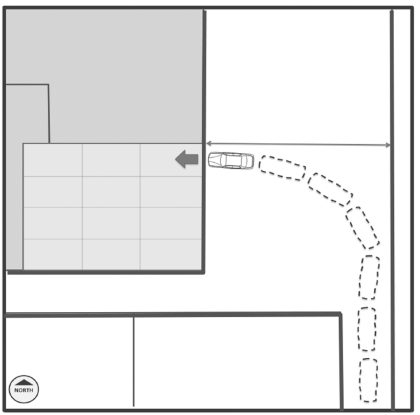

Case 1: Square

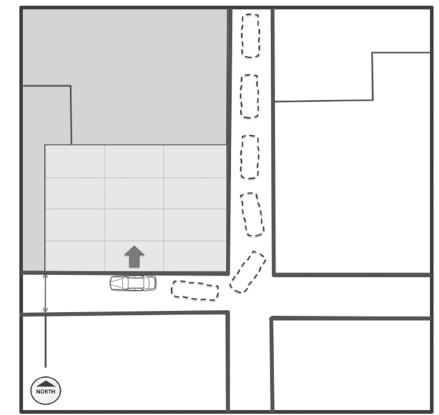

Case 2: Narrow street
Fig. 9. Flexibility in the accessibility to parking

overcome the perceived risk by the potential new residents to move into a city sector with a prior bad reputation. Finally, costs need to be competitive, also to overcome the customer's fears of refurbished versus new. This requires proper use of innovative and technologically advanced materials, construction processes, and solutions. These aspects will be further discussed in the following section.

\section{Economic Feasibility}

Urban rehabilitation at the district level is a complex and costly endeavor. In cases of significant degradation that have already resulted in most of the problems previously identified, it is usually only possible to implement successful rehabilitation initiatives in case there is public investment and clear political support. The main reasons for this are as follows:

- In inner districts, property is highly fragmented so that it is excessively complex, time-consuming, and costly for private investors to acquire the area to intervene;

- Even in cases where there is a significant level of desertification, in each building, there are usually one or two long-term tenants remaining in that block who might delay any potential rehabilitation intervention;

- There is a high level of physical constraint for the execution of the rehabilitation works, thus resulting in lengthy processes that require a significantly increased capital cost and risk for such rehabilitation projects; and

- The type of rehabilitation techniques is usually based on traditional construction techniques with a large proportion of in situ work and often excavation works that are characterized by increased uncertainties during construction that lead to added costs and delays.

The proposed model addresses the difficulties of excessive time, capital, complexity, and risk as follows:

- It generates new business activity, with the idea of a multipurpose building that offers various services at the level of each subsector, making them a driving force of urban regeneration because they make each subsector more attractive from a socioeconomic and functional performance point of view in terms of meeting the requirements of land use and as energy efficiency. This has the potential to attract specific investors to build and operate these multipurpose buildings in a replicable model (across the various subsectors of a single city or across multiple cities). The level of investment is contained and the combination of various services provides the basis for a profitable investment in itself, even without the real estate component of the rest of the buildings in each subsector. This new business activity is essential in upgrading the attractive conditions of these neighborhoods; and

- It promotes innovative off-site rehabilitation techniques for the upgrading of the existing buildings, greatly reducing the disruption in the neighborhood during the rehabilitation period, increasing the quality of the final product, reducing the intervention periods, and reducing the financial risk for the investors. These innovative processes also potentially provide self-construction possibilities, thus allowing lower-income families to remain in their upgraded houses instead of being directed to peripheral ghettos of the cities.

Being a global but flexible model, it greatly facilitates the task of providing local authorities with the technical capabilities to accompany and control these processes. The global nature of the model also means that it can benefit from the progressive cost reductions that are inherent to any process that becomes massproduced.

\section{Sustainability}

This conceptual model must also present significant potential improvements in promoting sustainable urban development. While at the building level, there exist quantitative methodologies based on life-cycle approaches (ISO_14001 2004) [EN 1993-1-8 (CEN 2005)], there are currently no generally accepted methodologies for the assessment of the sustainability at urban levels (Gervásio and Simões da Silva 2013). Nevertheless, considering the three usual dimensions of sustainability: environmental, economical, and social (Gervásio and Simões da Silva 2012), the following potential advantages are presented.

- Energy networking in the city quarter, thereby making smart low-cost use of old buildings.

- Battery storage and heat storage buildings for quarters.

- An information technology department, which manages the entire city quarter.

- Improved architectural typologies suitable for aging and diversifying societies.

- New steel-intensive solutions with beneficial thermal functions and a positive ecological balance.

- Connecting new buildings with existing buildings. Therefore, this effect will not be limited to some new buildings but will affect and rehabilitate entire city quarters, with the added benefits of a local distributed supply network. In particular for buildings with different uses and occupations, additional energy-saving potentials will result from a heat shift in the transition period from office use to residential use.

- Induction of mobility flows.

- Energy-efficient development structure.

- Resource-saving infrastructure.

- Water circulation systems.

- Efficient waste management.

- City quarters that follow energy saving and demographic change.

The interconnection between urban quarters and buildings with respect to architecture and urban planning, energy supply, health, and sociocultural requirements are treated.

The new conceptual model covers all of the relevant issues in sustainable building: from the rehabilitation and planning of an urban structure, to the proper use and appropriation of spaces from the residents, taking into account the occupancy flexibility, sustainable mobility, recreational, and functional aspects of the building, as well as the questions of maintenance, management, and cleaning, which are related to the environmental and the economic aspects. 


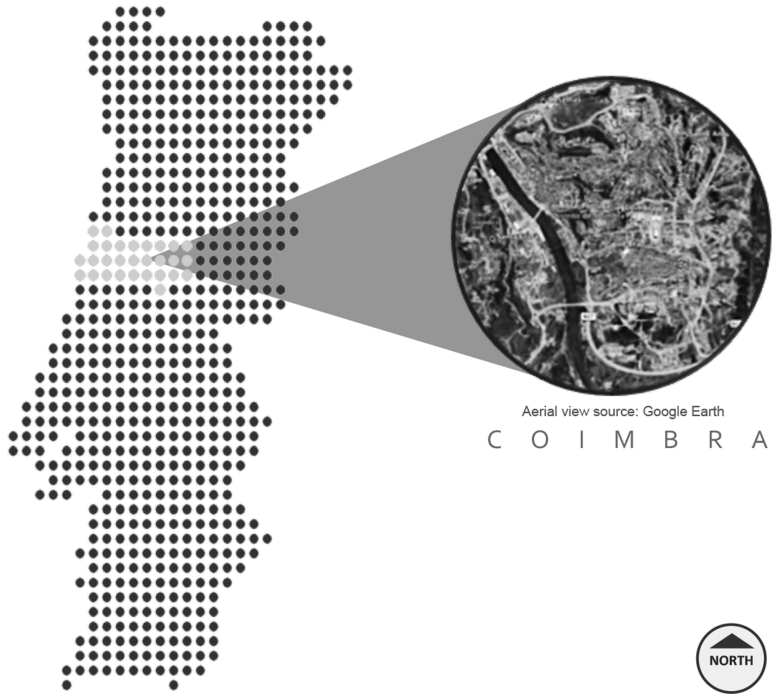

Fig. 10. Coimbra, Portugal

\section{Application to the City of Coimbra}

\section{General Description}

In order to illustrate the applicability of this conceptual model, Coimbra was chosen as a focal point. Coimbra is a medium-size city in Portugal, with a population of more than 100,000 inhabitants (Lopes 2000) and a territorial extension over 3,000 ha. It is located in the coastal region of Portugal, halfway between Lisbon and Oporto (Fig. 10).

The city lies mainly on the north bank of the Mondego River and its central business district includes part of its historical district. Currently, part of its appeal to many tourists is the charm of finding buildings from different periods of history, which harmonize the context, from Roman and pre-Roman buildings, to contemporary interventions such as the Mondego Green Park or the recent Rainha Santa and Pedro and Ines bridges. However, the most famous and well-recognized building in the city is the Paço das Escolas that belongs to the University of Coimbra, which was established in 1290 .

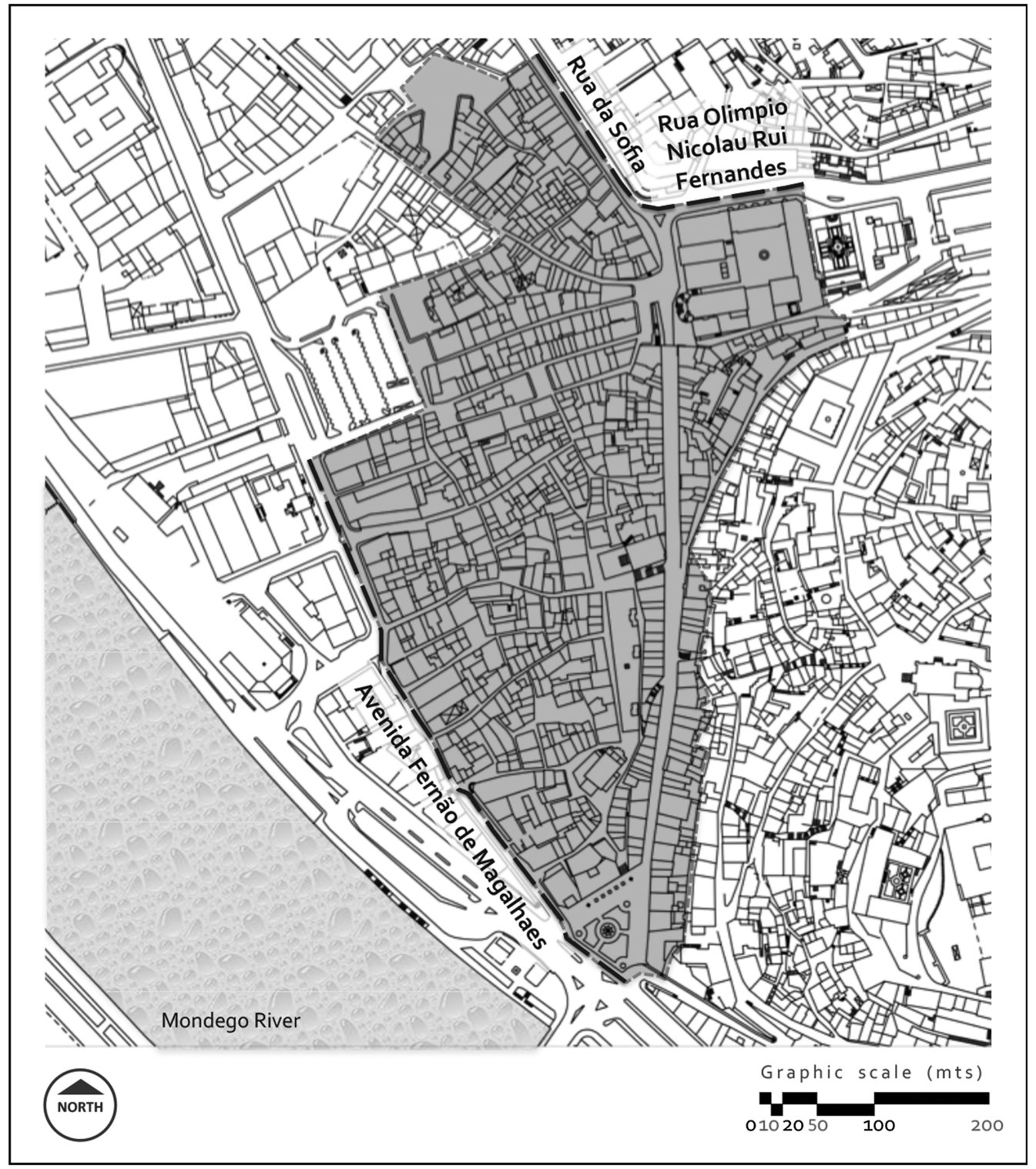

Fig. 11. Baixa of Coimbra, study area 


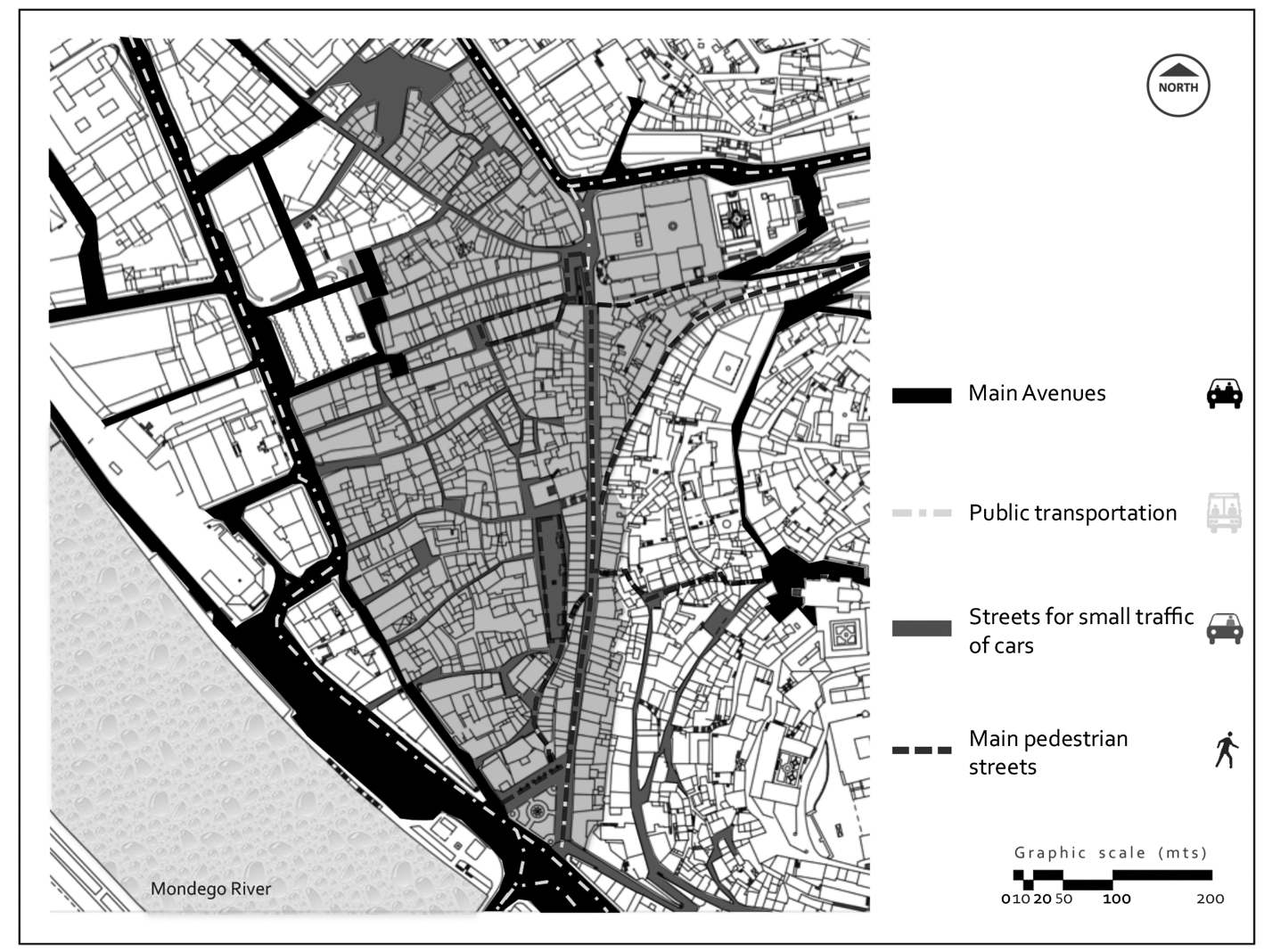

Fig. 12. Transportation

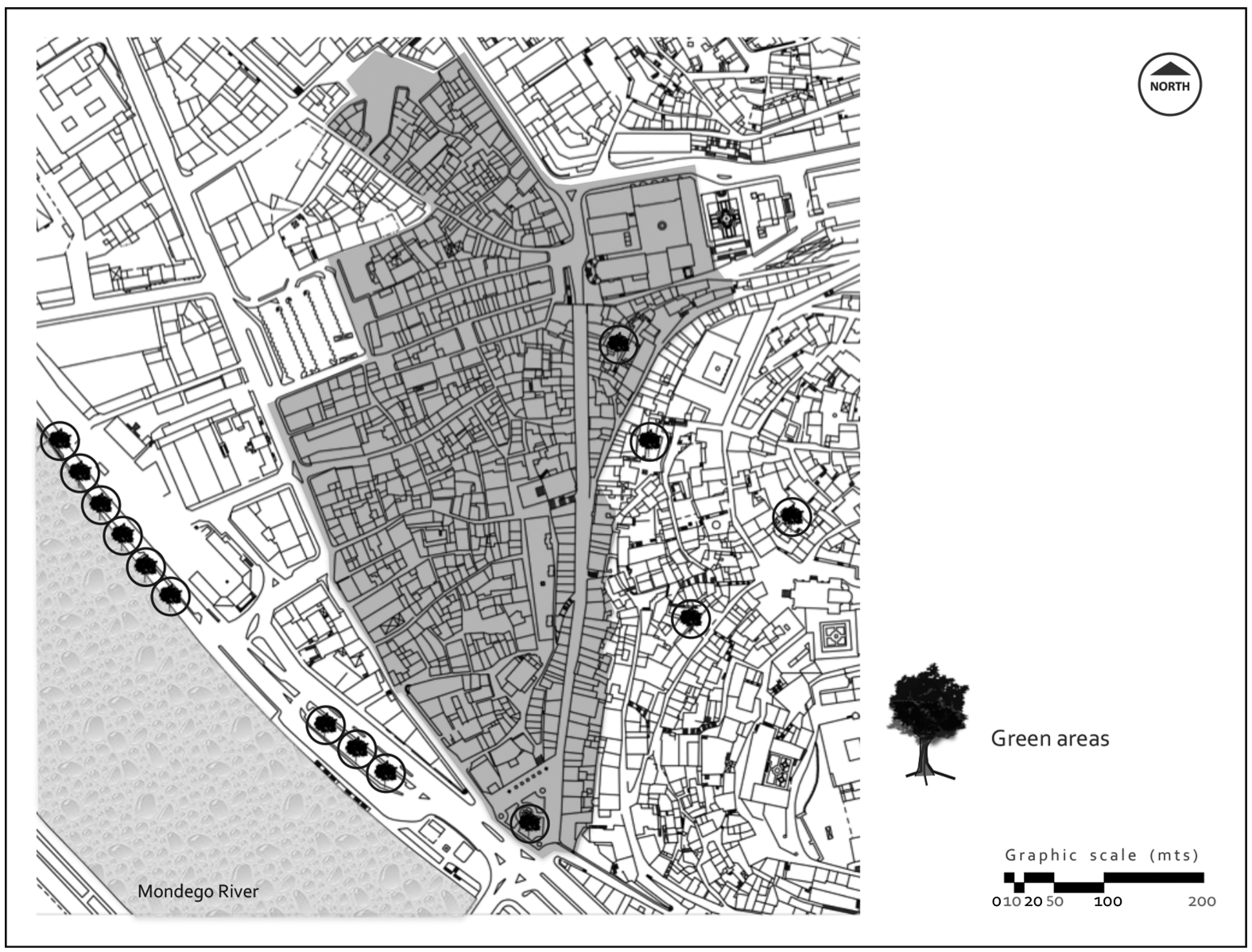

Fig. 13. Open green spaces 


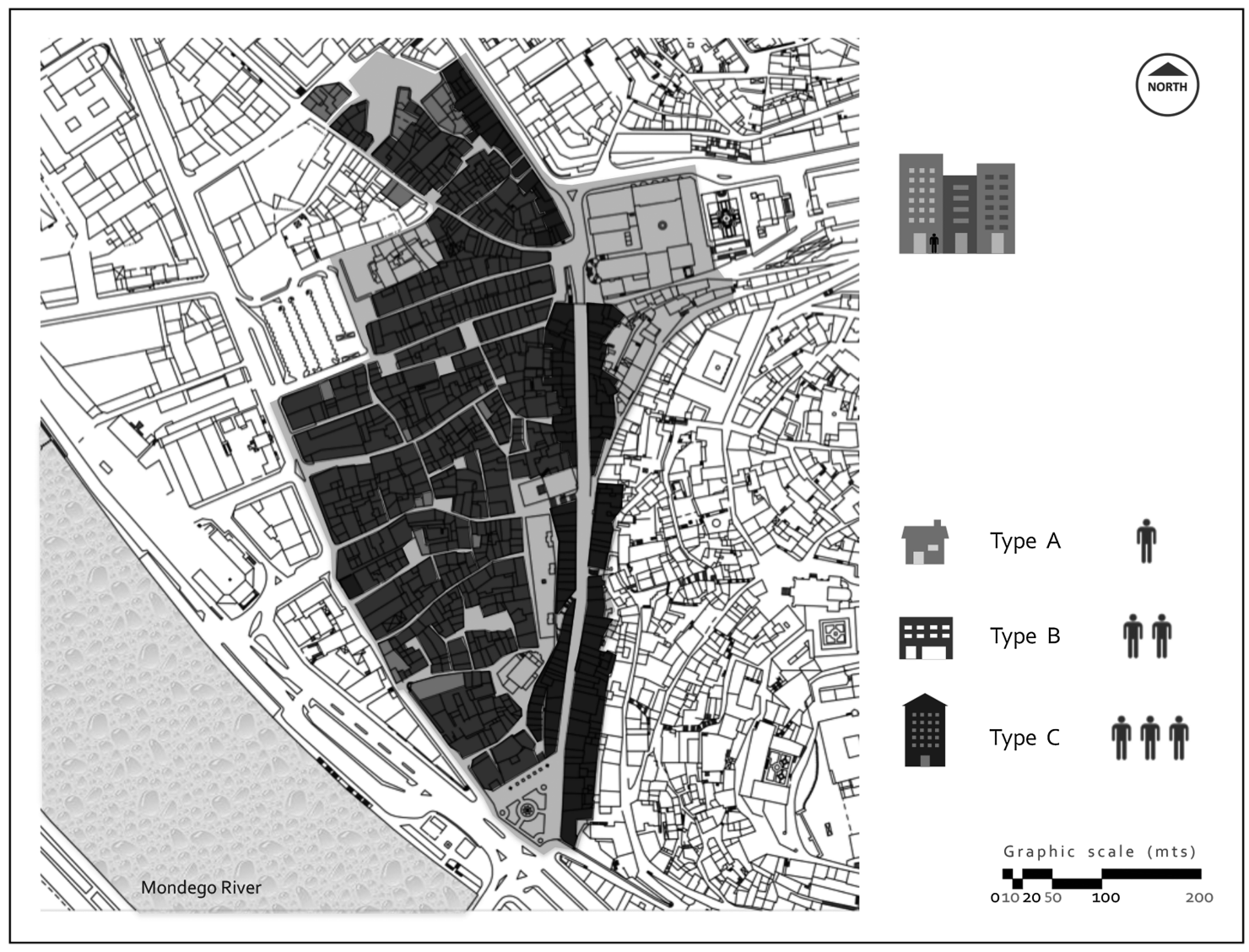

Fig. 14. Residential typologies

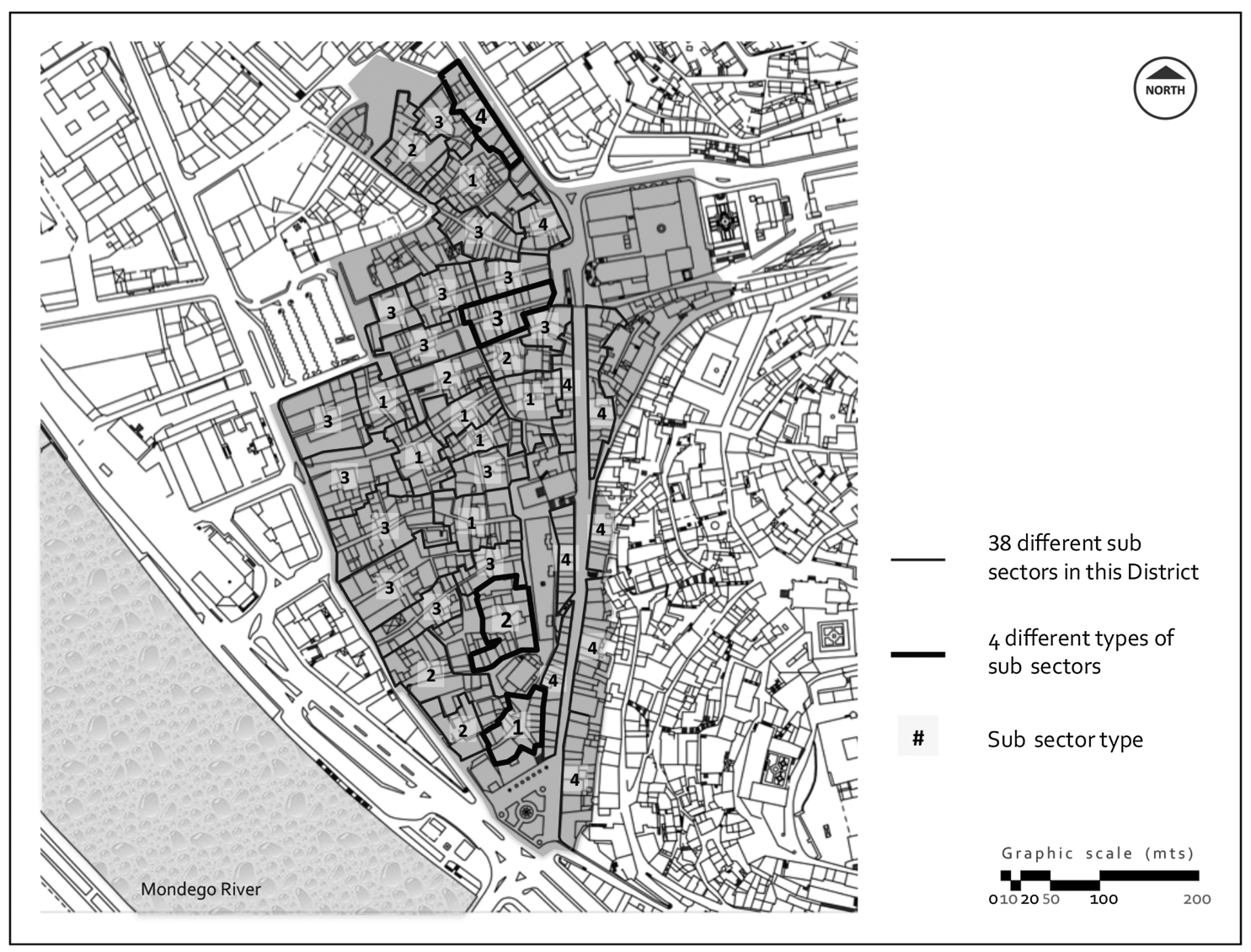

Fig. 15. Subsectors 


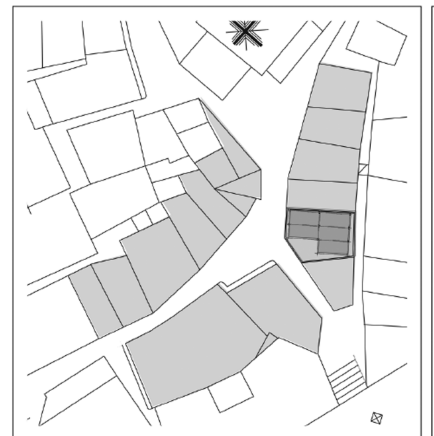

Multistreets

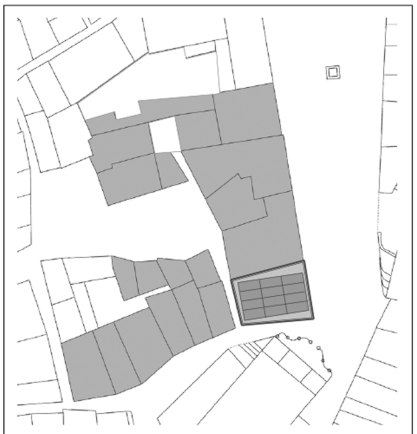

Perimeter streets

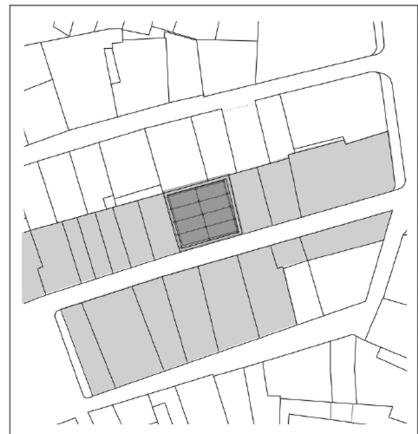

Middle street

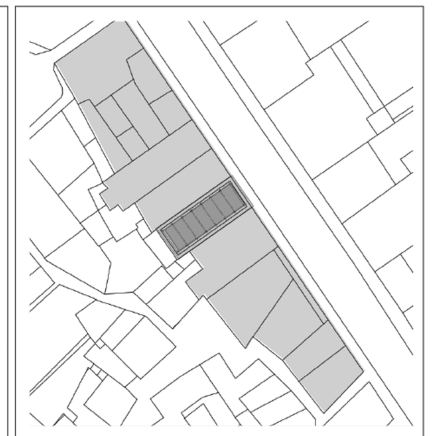

Linear side streets

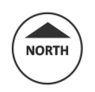

Graphic scale (mts)

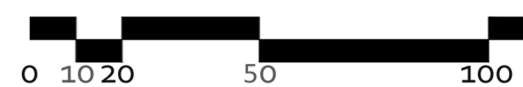

200

Fig. 16. Typologies of subsectors

Because of its topography, downtown Coimbra is divided into two main areas. Alta is the upper part and is largely occupied by the main complex of the University. Baixa is the lower part and is a medieval core, historically associated with the original core of the city; it is the city center of Coimbra and is primarily composed of the parish of São Bartolomeu and Santa Cruz. This was chosen as the study area because it corresponds to the part of the city where the urban physical deterioration, decreasing population, and accessibility problems can be seen.

The delimitation of the study area (sector), illustrated in Fig. 11, took into account some of the main streets of the zone, and concentrated on the part of the city with more residential buildings. The streets that delimitate the study area are Rua Olimpio Nicolau Rui Fernandes, Rua da Sofia, and Avenida Fernão de Magalhaes.

\section{Characterization of the Current Situation}

The sector defined in Fig. 11 is enclosed by main streets that allow the flow of traffic from the inside to the outside, but hinder the flow in the opposite situation (Fig. 12). In addition to the increased traffic flow, the increase in the use of cars has more negative aspects, such as the loss of ecological and sustainable culture, the decreasing health in people, and the demand for parking space. The latter has the secondary effect of increasing the spatial imprint of parked vehicles, creating additional delays, impairing local circulation, and is often deadening, dull, and hostile to pedestrians; it is also provided at the expense of other more productive investments (Manville and Shoup 2005). An additional negative aspect of the intensive use of vehicles and parking lots is the visual contamination that generates gray zones in the urban model of the city.

In the study area, traffic limitations exist for on-street parking and for finding public parking facilities, nevertheless, this situation doesn't avoid persuading people to use cars, and in a second effect, it reduces the walking opportunity in the area (Lotfi and Koohsari 2011).

In the case of Coimbra, the amount of open green spaces in the zone is minimal (Fig. 13); Portagem is the only major green urban space that gives a social and sustainable solution to all the study area.

With respect to public open spaces, a different scenario is noted as in this study area a few related spaces exist such as Praça 8 de Maio, Praça de Comercio, and so forth. However, some interaction with social activities that involves the local residents is still missing.
In addition to public spaces, some public buildings can be found that help in the interaction between users and spaces. The hours public buildings are open can determine the conception of living in the city and also the private spaces.

In terms of public spaces the different functions are government, religious, service, education, and culture. These buildings are partly responsible for the flow of people in the zone, as 9:00 a.m. to 7:00 p.m. are the working hours for the public buildings, leading to more people interacting in the streets and all the spaces. After 7:00 p.m. this flow of people decreases, becoming primarily a transit area for a few residents of the zone.

As this study is concentrated in the decrease of inhabitants, it is important to mention the private spaces or residential typologies of the zone (Fig. 14). Three types are identified: A, B, and C, each one representing a different density and showing diverse particularities. For example, in terms of density, Type $\mathrm{A}$ is the one with the least population density and Type $\mathrm{C}$ has more, but Type $\mathrm{B}$ has the most in this zone. Concerning the number of stories, Type A has one or two stories; Type B has three or four; and Type $\mathrm{C}$ has from five to seven. Finally, concerning function, Type A is mainly residential, while Types B and C are mixed. In almost all cases, buildings with shops on the first floor and residential use in the upper floors are found.

The study area is mainly residential. Almost 20 percent of these private buildings are in substandard condition or even abandoned. This is due to the complication of these buildings to maintain a

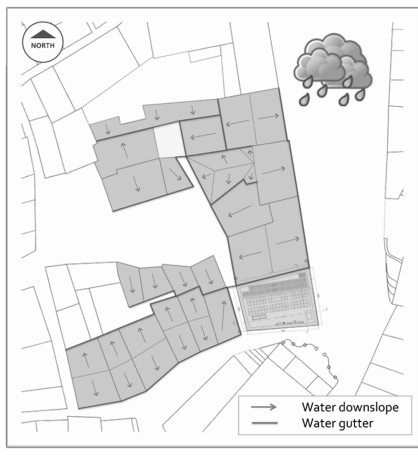

Rainwater harvesting

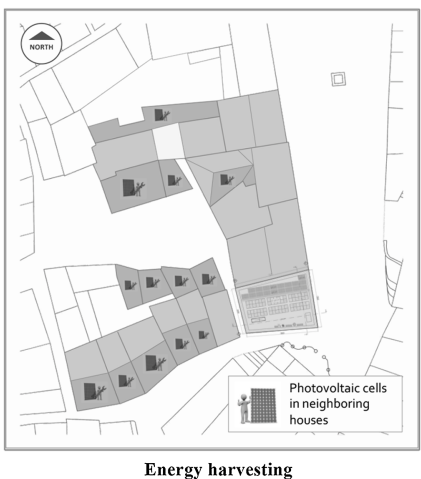

Energy harvesting
Fig. 17. Subsector systems 


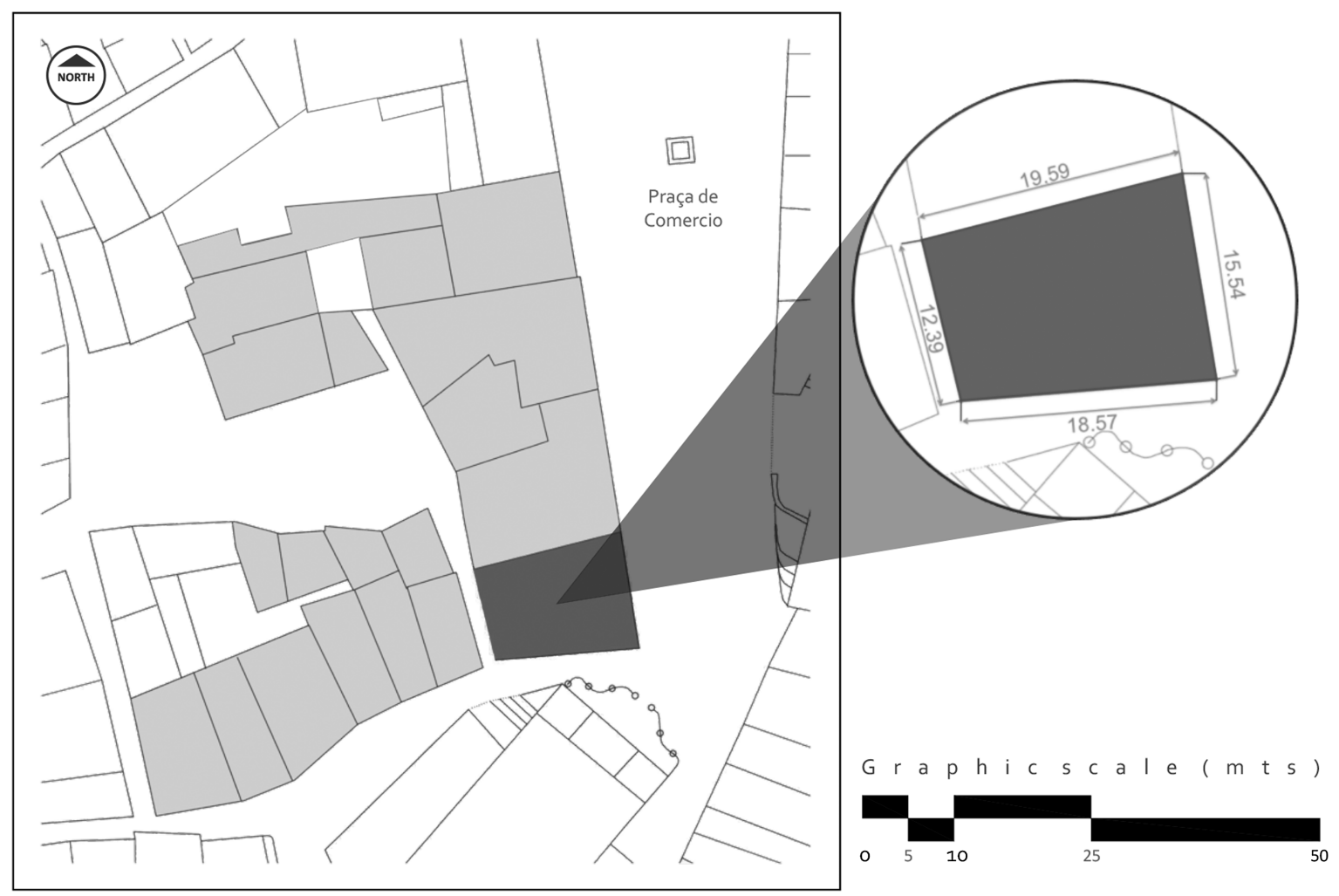

Fig. 18. Proposal for the multipurpose building subsector Case 2

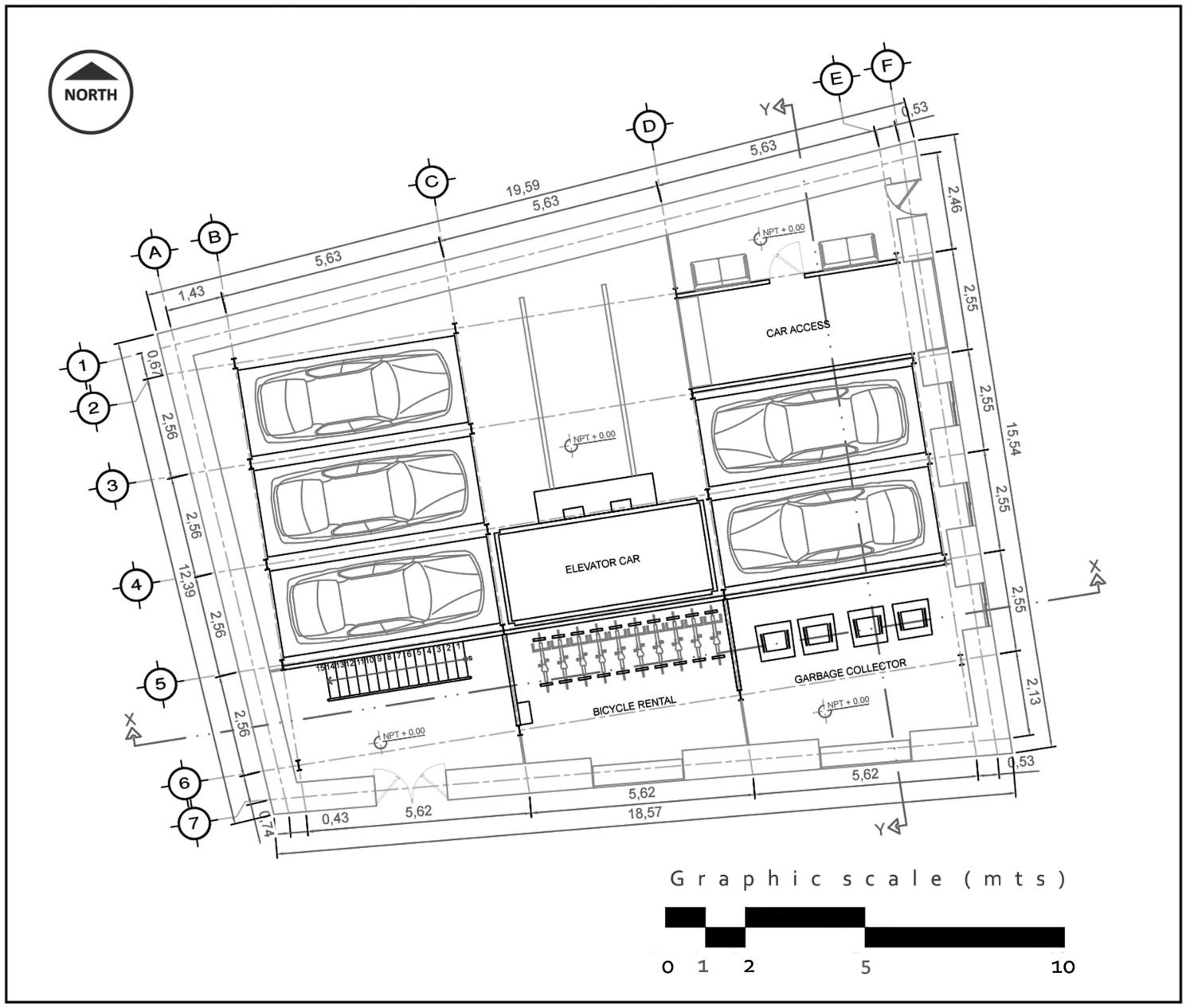

Fig. 19. First floor 
comfortable lifestyle because the majority of them are old buildings with inadequate organization of internal space and constant maintenance, the lack of individual parking that creates unnecessary costs for the residents, the existence of degraded thick walls, the poor thermal comfort conditions, and the lack of elevators.

\section{Urban-Level Implementation}

According to the definition of the typologies of subsectors in Fig. 2, the sector was divided into 38 subsectors (Fig. 15). This figure also illustrates the distribution of typologies in the sector, showing that the four typologies adequately cover all situations.

Fig. 16 details an example for each of the four typologies of subsectors.

For the implementation of multipurpose building of the subsector typology, Case 2 (perimeter streets) was selected [Fig. 16(b)].

Fig. 17 shows the relation between the multipurpose building with the existing buildings of the subsector and it exemplifies the implementation of a rainwater collection network and an integrated renewable energy production system using photovoltaic panels installed in the roofs with centralized management.

The idea of the renewable energy production system used in the multipurpose building follows the idea of the European project "The district heating and cooling in the U.K.," which is a smart grid to achieve local sustainable and affordable energy and which contributes to economic regeneration by the creation of district heating and cooling networks at the urban scale in the United Kingdom (Hawkey et al. 2013).

Likewise, the idea of the rainwater collection network presented in the multipurpose building tries to adapt the system of a communal rainwater tank designed in Australia, which provides an alternative urban water supply solution for reducing dependence on centralized water supply networks (Gurung and Sharma 2014).

\section{Multipurpose Building Implementation}

Fig. 18 illustrates the selected subsector, Case 2, and highlights the location of the multipurpose building. The various buildings have irregular shapes with interpenetrating volumes in some cases and the subsector includes an internal backyard. The subsector is accessible from two perimeter streets and a narrow footpath. The multipurpose building is located at the corner of the two streets.

The land plot has an irregular shape, with the following dimensions: $19.59 \mathrm{~m}$ facing north, $15.54 \mathrm{~m}$ facing east, $18.57 \mathrm{~m}$ facing south, and $12.39 \mathrm{~m}$ facing west.

Taking into account these dimensions, the requirement to maintain the outer facade walls, the need to provide parking, and the

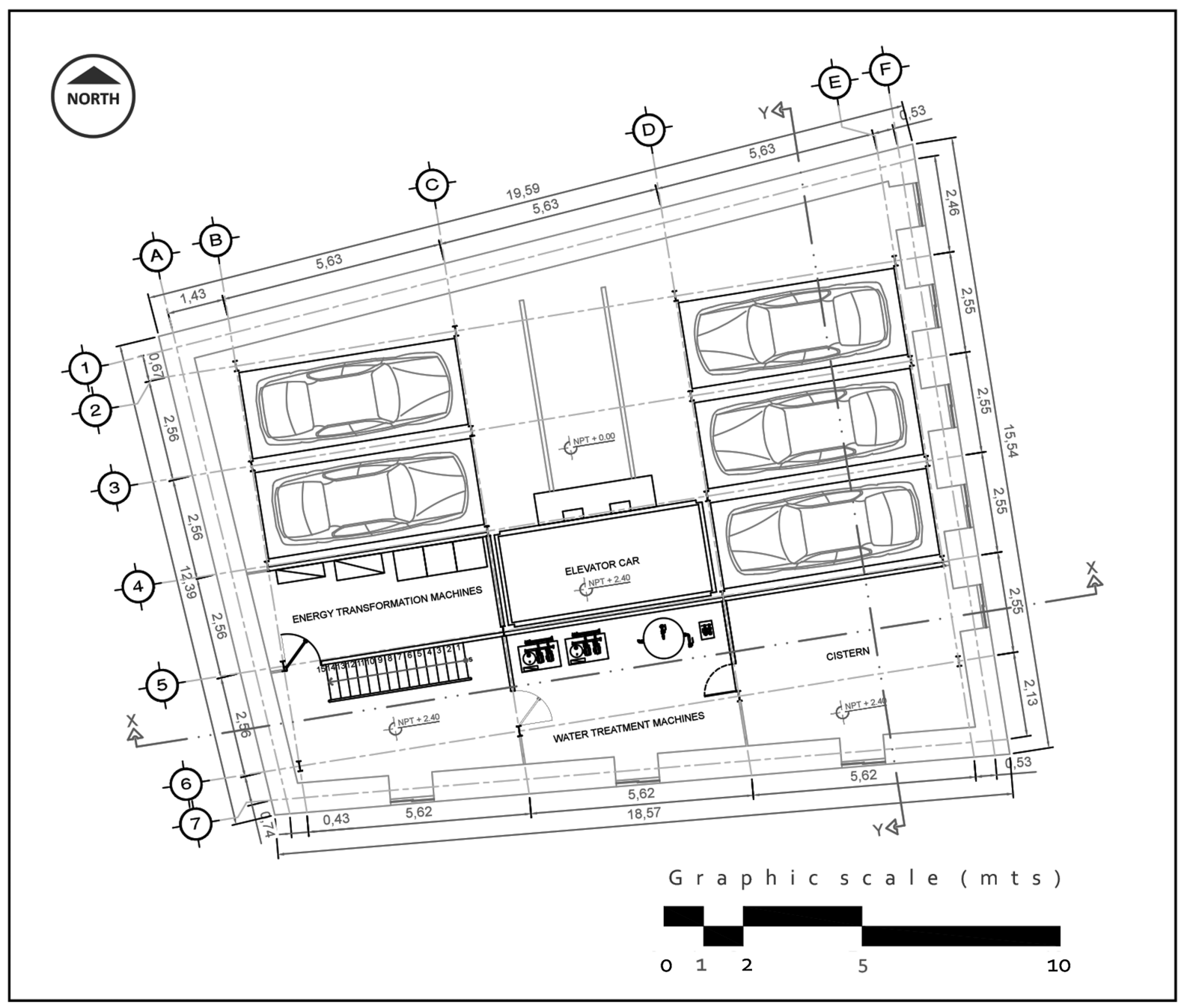

Fig. 20. Second floor 


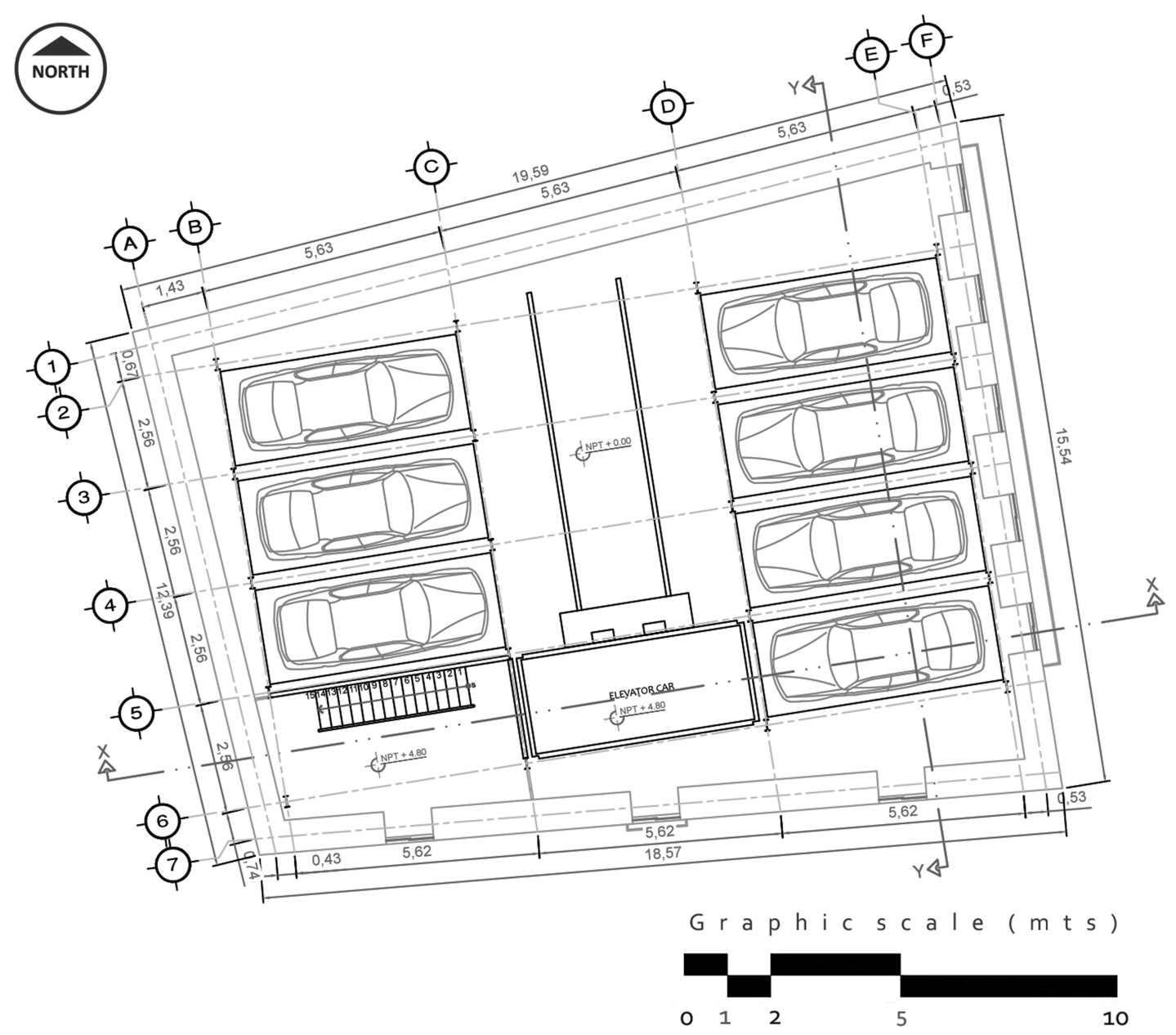

Fig. 21. Third/fourth/fifth floor

generation of resources to provide a comfortable environment in the existing buildings, the following modules were chosen: bicycle and motorcycle rental, parking lot, parking elevator, garbage collector, water treatment, cistern, energy-efficient development, maintenance stairs, horticulture, and photovoltaic cells. The building facade will be Type A (existing facade).

The resulting architectural layout plans are described as follows:

First-floor level $( \pm 0.00 \mathrm{~m})$. The entrance of the building provides entry for cars, access to the stairs for community services, parking of bicycles and motorcycles, garbage collector for the efficient waste management, five parking spaces, and the elevator for stacked car parking (Fig. 19).

As this multipurpose building is more an infrastructure than a social building, almost all the activities will have restricted access. The horticulture garden in the top of the building will provide social services. For this reason, on the first floor, each activity has its own gate and the connection between modules is prevented.

Second-floor level $(+2.40 \mathrm{~m})$. This is used for the management of resources: water treatment machines, cistern room, energy transformation room, five parking places, and the elevator for stacked car parking (Fig. 20). This floor has restricted access.

Third, fourth, and fifth floors. These three floor levels $(+4.80$, +7.20 , and $+9.60 \mathrm{~m}$ ) have the same architectural plan, consisting of seven parking places and the elevator for stacked car parking in each level (Fig. 21). These also have restricted access.

Roof $(+12.00 \mathrm{~m})$. This consists of a mixture of green area $\left(157 \mathrm{~m}^{2}\right)$ with the function of horticulture for social interaction and the photovoltaic panels $\left(61 \mathrm{~m}^{2}\right)$ to generate energy (Fig. 22).

Facades. The existing facades have to be kept, but with the appropriate maintenance and rehabilitation work.

Fig. 23 illustrates two sections of the building.

\section{Conclusions}

The objective of this paper is to provide a conceptual model for the sustainable rehabilitation and management of inner centers in European medium-size cities.

The conceptual model presented here redefines the way of living in a city center in an innovative way. It provides not just a specific intervention in a group of buildings, but also a new paradigm for sustainable urban management based on the implementation of an integrated process of rehabilitation. The model relies on a new multipurpose building that provides a series of functions and services such as parking, waste sorting, rainwater reuse, management and storage of electricity production from renewable energy sources, and social services for the residents, resulting in a low-cost 


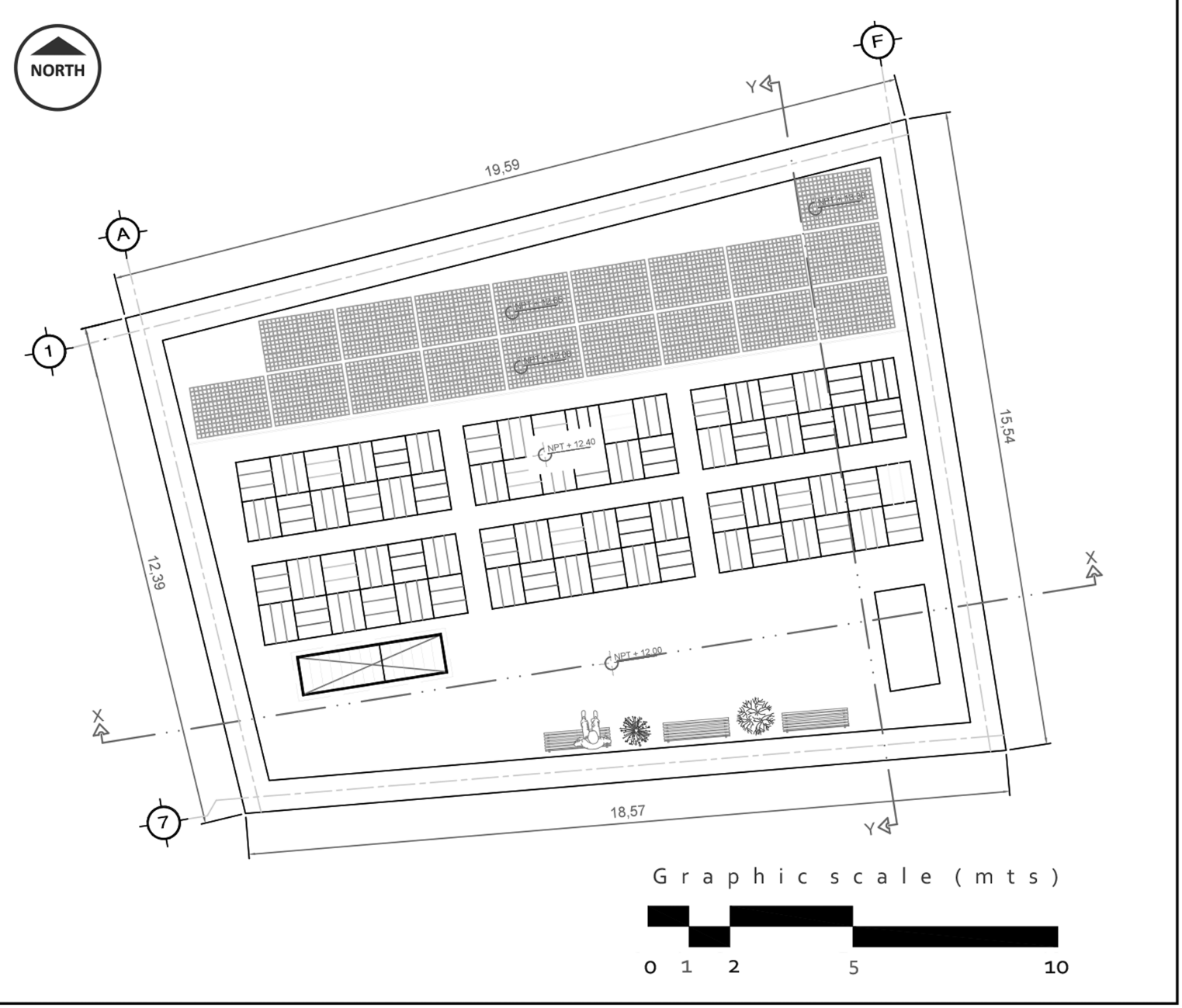

Fig. 22. Roof

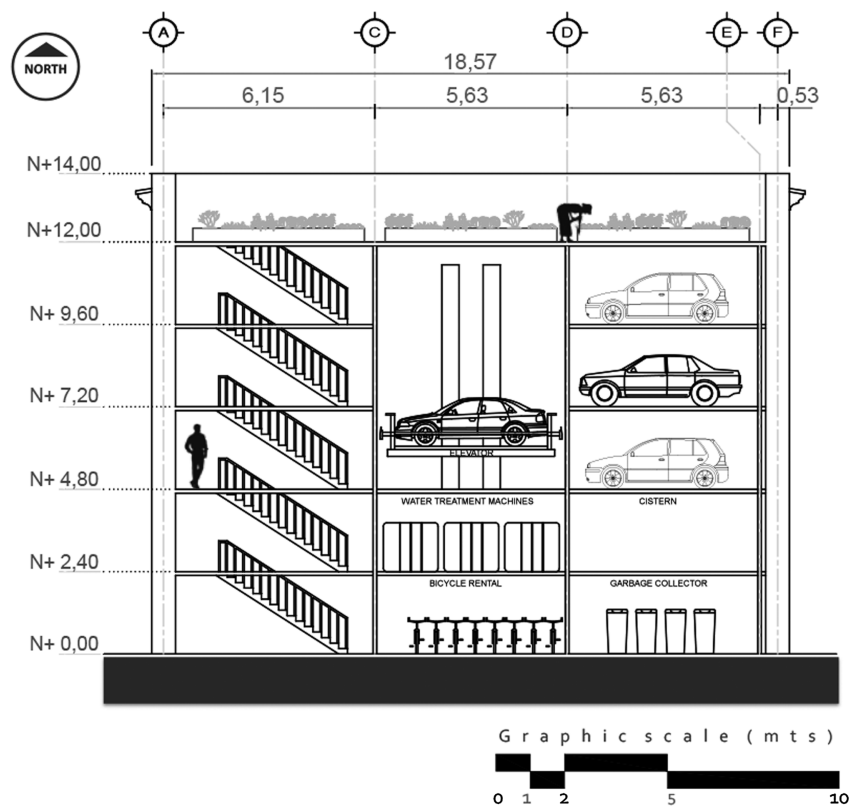

Section X - X'

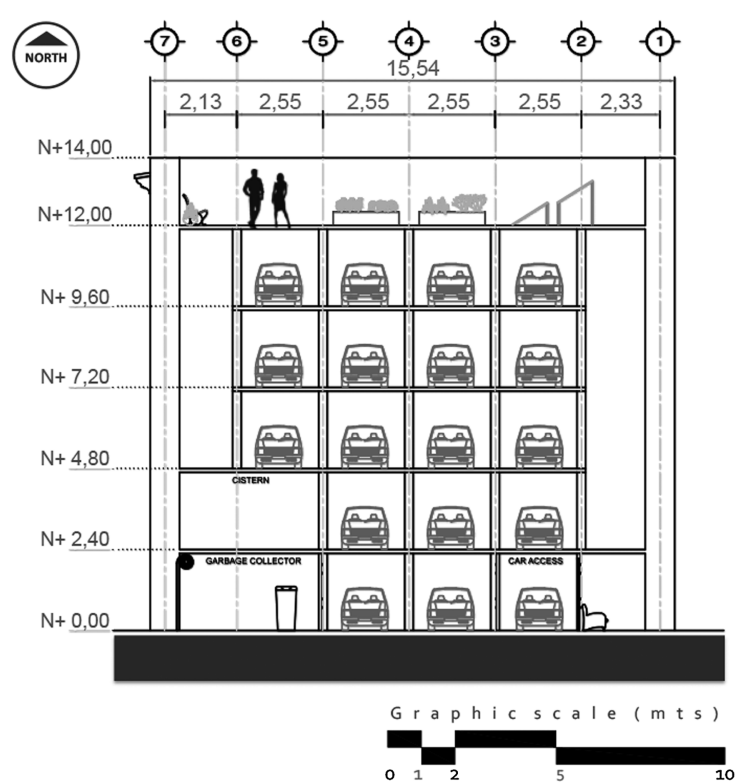

Section Y - Y'

Fig. 23. Sections 
solution for regenerating the existing neighborhoods and bringing quality of life to the residents.

As proof of this concept, the model is applied to the city center of Coimbra, Portugal, starting with the organization of the neighborhood into sectors and subsectors as the basic management units. Four different typologies were identified that cover all cases. Subsequently, at the building level, the multipurpose building was implemented, proving the applicability of the concept.

In conclusion, the general idea of this urban management model for the revitalization and redensification of inner-city neighborhoods is to function as a viable, sustainable, and adaptable alternative that leads to improving the quality of life in European cities, attracting new residents, and restoring a social spirit to urban centers.

It is further noted that nowadays, the generation of ideas and concepts to rehabilitate urban city centers have become a priority in the field of urban planning, architecture, engineering, and construction, and this model has the potential to contribute to this goal.

\section{References}

Alonso, S. (2011). Problemas ambientais nos centros urbanos, Novos Diálogos, Rio de Janeiro, Brasil (in Portuguese).

Arias, F. (2001). Problemática urbana actual, Edita el Instituto Juan de Herrera, Bruselas, Bélgica (in Spanish).

Bronsema, B., et al. (2004). "Performance criteria of buildings for health and comfort." ISIAQ-CIB Task Group TG 42.

CEN (European Committee for Standardization). (2005). "Eurocode 3: Design of steel structures. Part 1.8: Design of joints." EN 1993-1-8, Brussels, Belgium.

Codoban, N., and Kennedy, C. A. (2008). "Metabolism of neighborhoods." J. Urban Plann. Dev., 10.1061/(ASCE)0733-9488(2008)134:1(21), 21-31.

Dawood, S., Crosbie, T., Dawood, N., and Lord, R. (2013). "Designing low carbon buildings: A framework to reduce energy consumption and embed the use of renewables." Sustainable Cities Soc., 8, 63-71.

Europa-Global Partnership for Sustainable Development. (2013). "Summaries of EU legislation." 〈http://europa.eu/legislation_summaries/ external_trade/128015_en.htm〉 (Sep. 2013).

Europa-URBAN II. (2013). "Summaries of EU legislation.” 〈http://europa .eu/legislation_summaries/regional_policy/provisions_and_instruments/ g24209_en.htm>.

European Capital of Culture. (2009). The road to success from 1985 to 2010, European Communities, Belgium.

European Commission. (2009). "Promoting sustainable urban development in Europe: Achievements and opportunities.” European Union Regional Policy, Brussels, Belgium.

European Commission. (2011). "Cities of tomorrow. Challenges, visions, ways forward." European Union Regional Policy, Brussels, Belgium, 91-93.

European Energy Programme for Recovery (EEPR). (2013). "European commission." 〈http://ec.europa.eu/energy/eepr/〉 (Sep. 2013).

European Parliament. (2010). "Directive 2010/31/EU of the European Parliament and of the Council of 19 May 2010 on the energy performance of buildings (recast)." Off. J. Eur. Union., L153-13L153-35.

Fernández, O. (2012). "People, places, and history. Towards the sustainability of social life in traditional environments." Sustainable development, policy and urban development-Tourism, life science, management and environment, C. Ghenai, ed., InTech, Rijeka, Croatia, 238-252.

Gervásio, H., Santos, P., Simões da Silva, L., and Lopes, A. (2010). "M. G. Influence of thermal insulation on the energy balance for cold-formed buildings." Adv. Steel Constr., 6(2), 742-766.

Gervásio, H., and Simões da Silva, L. (2012). "A probabilistic decision making approach for the sustainable assessment of infrastructures." Expert Syst. Appl., 39(8), 7121-7131.
Gervásio, H., and Simões da Silva, L. (2013). "Life-cycle social analysis of motorway bridges.” J. Struct. Infrastruct. Eng., 9(10), 1019-1039.

Golubchikov, O., and Badyina, A. (2012). "Sustainable housing for sustainable cities: A policy framework for developing countries." United Nations Human Settlements Program (UN-Habitat), UNON, Nairobi, Kenya.

Goulden, M., Bedwell, B., Rennick-Egglestone, S., Rodden, T., and Spence, A. (2014). "Smart grids, smart users? The role of the user in demand side management." Energy Res. Social Sci., 2, 21-29.

Gurung, T., and Sharma, A. (2014). "Communal rainwater tank systems design and economies of scale." J. Cleaner Prod., 67, 26-36.

Hawkey, D., Webb, J., and Winskel, M. (2013). "Organisation and governance of urban energy systems district heating and cooling in the U.K.' J. Cleaner Prod., 50, 22-31.

ISO (International Organization of Standardization). (2004). "Environmental management systems: Specification with guidance for use." ISO 14001, Geneva.

JESSICA. (2013). "Joint European support for sustainable investment in city areas project." (http://ec.europa.eu/regional_policy/thefunds/ instruments/jessica_en.cfm\#1〉 (Sep. 2013).

Labory, F., et al. (2008). "Energy efficient buildings through innovative systems in steel." Final Rep., European Commission, Research Fund for Coal and Steel, Luxembourg, 3-5.

Lawson, R., et al. (2008). "Promotion of steel in sustainable and adaptable buildings." Final Rep., European Commission, Research Fund for Coal and Steel, Luxembourg.

Lawson, R., et al. (2013). "Renovation of buildings using steel technologies." Final Rep., European Commission, Research Fund for Coal and Steel, Luxembourg.

Leduc, W., and Van Kann, F. (2013). "Spatial planning based on urban energy harvesting toward productive urban regions." J. Cleaner Prod., 39, 180-190.

Li, Z., Boyle, F., and Reynolds, A. (2010). "Rainwater harvesting and greywater treatment systems for domestic application in Ireland." Desalination, 260(1-3), 1-8.

Lipovetsky, G. (2003). "Burn the media? Overcrowding and individualization. The suburban unconscious, or stories of nowhere." Quaderns d'arquitectura I urbanisme, 237, 14-25.

Lopes, C. (2000). "City center revitalization in Portugal. Lessons from two medium-size cities." Cities, 17(1), 19-31.

Lotfi, S., and Koohsari, M. (2011). "Neighborhood walkability in a city within a developing country." J. Urban Plann. Dev., 10.1061/(ASCE) UP.1943-5444.0000085, 402-408.

Madeira, C. A. C. L. (2009). "A Reabilitação Habitacional em Portugal: Avaliação dos Programas RECRIA, REHABITA, RECRIPH E SOLARH." Master thesis, Faculdade de Arquitetura da Universidade Técnica de Lisboa, Lisboa, Portugal (in Spanish).

Manville, M., and Shoup, D. (2005). "Parking, people, and cities." J. Urban Plann. Dev., 10.1061/(ASCE)0733-9488(2005)131:4(233), 233-245.

Nijkampp, P., and Perrels, A. (1994). Sustainable cities in Europe, Earthscan Publications, London.

Oc, T., and Tiesdell, S. (1998). "City center management and safer city centers: Approaches in Coventry and Nottingham." Cities, 15(2), $85-103$.

Palla, A., Gnecco, I., Lanza, L., and La Barbera, P. (2012). "Performance analysis of domestic rainwater harvesting systems under various European climate zones." Resour. Conserv. Recycl., 62, 71-80.

Rahaman, K., Lourenço, J., and Viegas, J. (2012). "Perceptions of pedestrians and shopkeepers in European medium-sized cities: Study of Guimarães, Portugal." J. Urban Plann. Dev., 10.1061/(ASCE)UP .1943-5444.0000094, 26-34.

Richner, P. (2013). "The transformation of the existing building stock: A precondition for a sustainable future." Concrete Repair, Rehabilitation and Retrofitting III (ICCRRR), M. G. Alexander, H.-D. Beushausen, F. Dehn, and P. Moyo, eds., Taylor \& Francis, 11-12.

Sánchez, F. (2009). "Intencionespara un nuevocentro. Revitalización de CentrosHistóricos." VII Encuentro Internacional, 1st Ed., Centro Cultural de España, México, 39-43 (in Spanish). 
Santos, P., Gervásio, H., Simões da Silva, L., and Gameiro, A. (2011). "Influence of climate change on the energy efficiency of light-weight steel residential buildings." Civ. Eng. Environ. Syst., 28(4), 325-352.

Santos, P., Simões da Silva, L., Gervásio, H., and Gameiro, A. (2010). "Parametric analysis of the thermal performance of light steel residential buildings in Csb climatic regions." J. Build. Phys., 35(1), 7-53.

Servicio de Estudios, Planificación y Presupuestos. (2010). Políticas de Rehabilitación y Regeneración urbana en Europa, San Sebastián, Spain (in Spanish).
Southworth, M. (2005). “ Designing the walkable city.” J. Urban Plann. Dev., 10.1061/(ASCE)0733-9488(2005)131:4(246), 246-257.

Temelová, J., and Dvoráková, N. (2012). "Residential satisfaction of elderly in the city center: The case of revitalizing neighborhoods in Prague.” Cities., 29(5), 310-317.

Urry, J. (2003). "Automobility and car culture. The suburban unconscious, or stories of nowhere." Quaderns d'arquitectura I urbanisme, 237, 76-85.

WÖHR. (2012). “Slimparker.” 〈http://www.woehr.de/en/〉 (Feb. 2014). 